\title{
Sensorless Control of Induction Motor Supplied by Current Source Inverter
}

\author{
Marcin Morawiec
}

Additional information is available at the end of the chapter

http://dx.doi.org/10.5772/51133

\section{Introduction}

The circuits used for power conversion applied in drives with induction motor (IM) are classified into two groups: voltage source inverters (VSI) and current source inverters (CSI). The VSI were used more often than the CSI because of their better properties. Nowadays, the development of power electronics devices has enormous influence on applications of systems based on the CSI and creates new possibilities.

In the 1980s the current source inverters were the main commonly used electric machine feeding devices. Characteristic features of those drives were the motor electromagnetic torque pulsations, the voltage and current with large content of higher harmonics. The current source inverter was constructed of a thyristor bridge and large inductance and large commutation capacitors. Serious problems in such drive systems were unavoidable overvoltage cases during the thyristor commutation, as the current source inverter current is supplied in a cycle from a dc-link circuit to the machine phase winding. The thyristor CSI has been replaced by the transistor reverse blocking IGBT devices (RBIGBT), where the diode is series-connected and placed in one casing with transistor. The power transistors like RBIGBT or Silicon Carbide (SiC) used in the modern CSIs guarantee superior static and dynamic drive characteristics.

The electric drive development trends are focused on the high quality system. The use of current sources for the electric machine control ensures better drive properties than in case of voltage sources, where it may be necessary to use an additional passive filter at the inverter output. The Pulse width modulation (PWM) with properly chosen dc-link inductor and input-output capacitors result in sinusoidal inverter output currents and voltages. Methods of calculating proper inductance in dc-link were proposed in [Glab (Morawiec) M. et. al., 2005, Klonne A. \& Fuchs W.F., 2003, 2004]. Properties of dc-link circuit of the Current Source Converter (CSC) force the utilization of two fully-controlled inverters to supply 
system with electric motor. The first of them - CSI - generates the current output vector to supply the induction motor. The second one - Current Source Rectifier (CSR) - generates a DC voltage to supply a dc-link circuit. The strategy for controlling the output current vector of CSI can be realized in two ways [Glab (Morawiec) M. et. al., 2005, Klonne A. \& Fuchs W.F., 2003, Kwak S. \& Toliyat H.A., 2006]. First of them is based on changes of modulation index while the value of current in dc-link circuit remains constant [Klonne A. \& Fuchs W.F., 2003]. The second method is based on changes of dc-link current. In this case the CSI is working with constant, maximum value of PWM modulation index. Control of modulation index in CSI is used in drive systems, where high dynamic of electromagnetic torque should be maintained [Klonne A. \& Fuchs W.F., 2003]. High current in dc-link circuit is a reason for high power losses in CSI. The simplified control method is the scalar control: current to slip (I/s). This method is very simple to implement, but the drive system has average performance (only one controller is necessary, the current in dc-link is kept at constant value by PI controller).

The drive system quality is closely connected with the machine control algorithm. The space vector concept, introduced in 1959 by Kovacs and Racz, opened a new path in the electric machine mathematical modelling field. The international literature on the subject presents drive systems with the CSI feeding an induction motor with the control system based on the coordinate system orientation in relation to the rotor flux vector (FOC - Field Oriented Control). Such control consisted of the dc-link circuit current stabilization [Klonne A. \& Fuchs W.F., 2003]. In such control systems the control variables are the inverter output current components. This control method is presented in [Nikolic Aleksandar B. \& Jeftenic Borislav I.], where the authors analyze control system based on direct torque control. The control process where the control variable is the inverter output current may be called current control of an induction motor supplied by the CSI.

Another control method of a current source inverter fed induction motor is using the link circuit voltage and the motor slip as control variables. That type of control may be called voltage control of a CSI fed induction motor, as the dc-link circuit voltage and angular frequency of current vector are the control variables. Proposed control strategy bases on nonlinear multi-scalar control [Glab (Morawiec) M. et. al., 2005, ]. The nonlinear control may result in better properties in case if the IM is fed by CSI. To achieve independent control of flux and rotor speed, new nonlinear control scheme is proposed. In this control method the inverter output currents are not controlled variables. The voltage in dc-link and pulsation of output current vector are the controlled variables which can be obtained by nonlinear transformations and are proposed by authors in [Krzeminski Z., 1987, Glab (Morawiec) M. et. al., 2005, 2007]. The multi-scalar model is named the extended one because the mathematical model contained dc-link current and output capacitors equations. This full mathematical model of induction machine with the CSI is used to derive new multi-scalar model. In proposed method the output current vector coefficients are not controlled variables. The output current vector and the flux vector are used to achieve new multi-scalar variables and new multi-scalar model. The control system structure may be supported on PI controllers and nonlinear decouplings or different controllers e.g. sliding mode controllers, the backstepping control method or fuzzy neural controller. 


\section{Structure of the drive system supplied by CSI or CSC}

The simplified configuration of the drive system with the CSI is presented in the Fig. 1. The integral parts of the system are the inductor in dc-link and the output capacitors. In the Fig. 1 the structure with the chopper as an adjustable voltage source is presented.

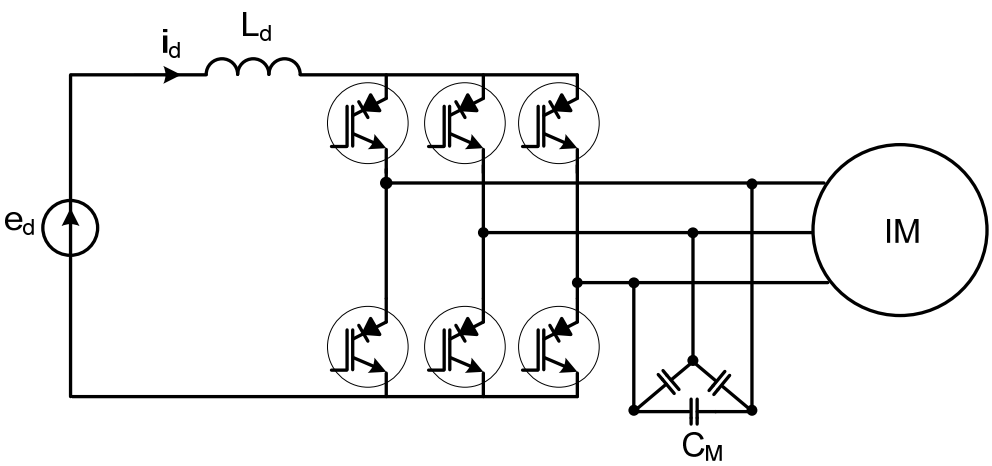

Figure 1. The CSI with the chopper

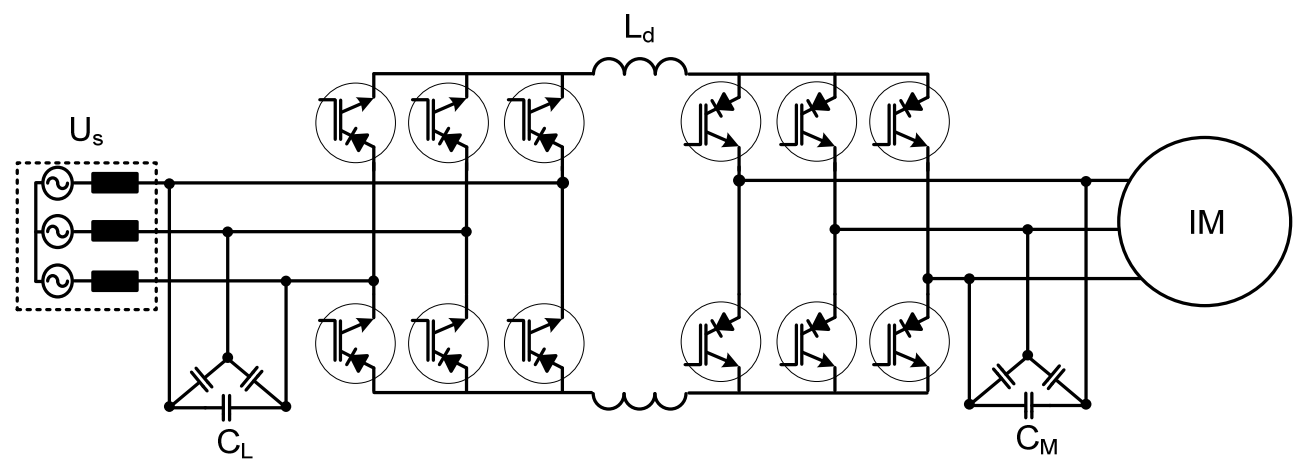

Figure 2. The Current source converter

The chopper with the small inductor $\mathrm{Ld}(\mathrm{a}$ few $\mathrm{mH}$ ) forms the large dynamic impedance of the current source. In the proposed system the transistors forms commutator which transforms DC current into AC current with constant modulation index. The current is controlled by voltage source ed in dc-link. In this way the system with CSI remains voltage controlled and the differential equation for dc-link may be integrated with differential equation for the stator. The inductor limits current ripples during commutations of transistors. The transistors used in this structure are named the reverse blocking IGBT transistors (RBIGBT).

In order to avoid resonance problem the CSI or CSC structure parameters (input-output capacitors and inductor) ought to be properly chosen. The transistor CSI or CSC structures should guarantee sinusoidal stator current and voltage of IM if the parameters are selected by iteration algorithm. 


\subsection{The iteration algorithm selection of the inductor and input-output capacitors}

The inductance in dc-link $\mathrm{Ld}$ may be calculated as a function of the integral versus time of the difference of input voltage ed and output voltage ud in dc-link [Glab (Morawiec) M. et. al., 2005, Klonne A. \& Fuchs W.F., 2003, 2004]. Calculating an inductance from [Glab (Morawiec) M. et. al., 2005, Klonne A. \& Fuchs W.F., 2003] may be not enough because of the resonance problem. The parameters could be determined by simple algorithm.

Two criteria are taken into account:

- Minimization of currents ripples in the system

- Minimization of size and weight.

The first criteria can be defined as:

$$
w_{i}=\frac{\Delta i_{d \max }}{i_{d}}
$$

where

$\Delta \mathrm{idmax}_{\mathrm{d}}$ is $\max \left(\mathrm{i}_{\mathrm{dmax}}\left(\mathrm{t}_{1}\right)-\mathrm{i}_{\mathrm{dmin}}\left(\mathrm{t}_{2}\right)\right)$,

id is average value of dc-link current in one period.

The current ripples in dc-link has influence on output currents and commutation process. According to this, the $\mathrm{wi}_{\mathrm{i}}$ factor, $\mathrm{THD}_{\mathrm{i}}$ stator and $\mathrm{THD}_{\mathrm{u}}$ stator must be taken into account. Optimal value of inductance $\mathrm{Ld}_{\mathrm{d}}$ and output $\mathrm{C}_{\mathrm{M}}$ ensure performance of the drive system with sinusoidal output current and small THD. In Fig. 3 the iteration algorithm for choosing the inductor and capacitor is shown. In every step of iteration new values $\mathrm{w}_{\mathrm{i}}, \mathrm{THD}_{\mathrm{i}}, \mathrm{THD}_{\mathrm{u}}$ are received. In every of these steps new values are compared with predetermined value wip, THDip, THD up and:

$\mathrm{N}$ is number of iteration,

$\mathrm{THD}_{\mathrm{i}}$ - stator current total harmonic distortion,

$\mathrm{THD}_{\mathrm{u}}$ - stator voltage total harmonic distortion. Number of iteration is set for user.

In START the initial parameters are loaded. In block Set $\mathrm{Ld}_{d}$ inductance of the inductor is set. In Numerical process block the simulation is started. In next steps $\mathrm{THD}_{\mathrm{i}}, \mathrm{THD}_{\mathrm{u}}$ and $\mathrm{w}_{\mathrm{i}}$ coefficient are calculated. THDi, THD $\mathrm{u}$ and $\mathrm{w}_{\mathrm{i}}$ coefficient are compared with predetermined value. If YES then $\mathrm{C}_{M}$ is setting, if $\mathrm{NO}$ the new value of $\mathrm{Ld}$ must be set. Comparison with predetermined value is specified as below:

$$
\left\{\begin{array}{l}
T H D_{i p \max } \leq T H D_{i}(i) \leq T H D_{i p \min } \\
T H D_{u p \max } \leq T H D_{u}(i) \leq T H D_{u p \min } \\
\Delta i_{d p \max } \leq \Delta i_{d}(i) \leq \Delta i_{d p \min }
\end{array}\right\}
$$

where 
$\Delta \mathrm{i}_{\mathrm{dpmax}}-$ maximum value for $\mathrm{wi}$ coefficient,

$\Delta \mathrm{i}_{\mathrm{dpmin}}-$ minimum value for $\mathrm{wi}$ coefficient,

$\mathrm{THD}_{\text {ipmax }}$ THD $\mathrm{D}_{\text {umax }}$ - maximum predetermined value of THD for range $\left(\Delta \mathrm{Ld}, \Delta \mathrm{CM}_{\mathrm{M}}\right)$,

$\mathrm{THD}_{\text {ipmin, }}$ THD $\mathrm{upmin}_{-}$minimum predetermined value of THD $\left(\Delta \mathrm{Ld}_{\mathrm{d}} \Delta \mathrm{C}_{\mathrm{M}}\right)$,

$\Delta \mathrm{Ld}$ - interval of optimal value $\mathrm{Ld}$,

$\Delta \mathrm{C}_{\mathrm{M}}$ - interval of optimal value $\mathrm{C}_{\mathrm{M}}$.

For optimal quality of stator current and voltage in a drive system THD $\mathrm{i}$ ought to be about $1 \%, \mathrm{THD}_{\mathrm{u}}<2 \%$ and $\mathrm{w}_{\mathrm{i}}<15 \%$ in numerical process. Estimated CSC parameters by the iteration algorithm are shown in Fig. 4 and 5 or Table 1.

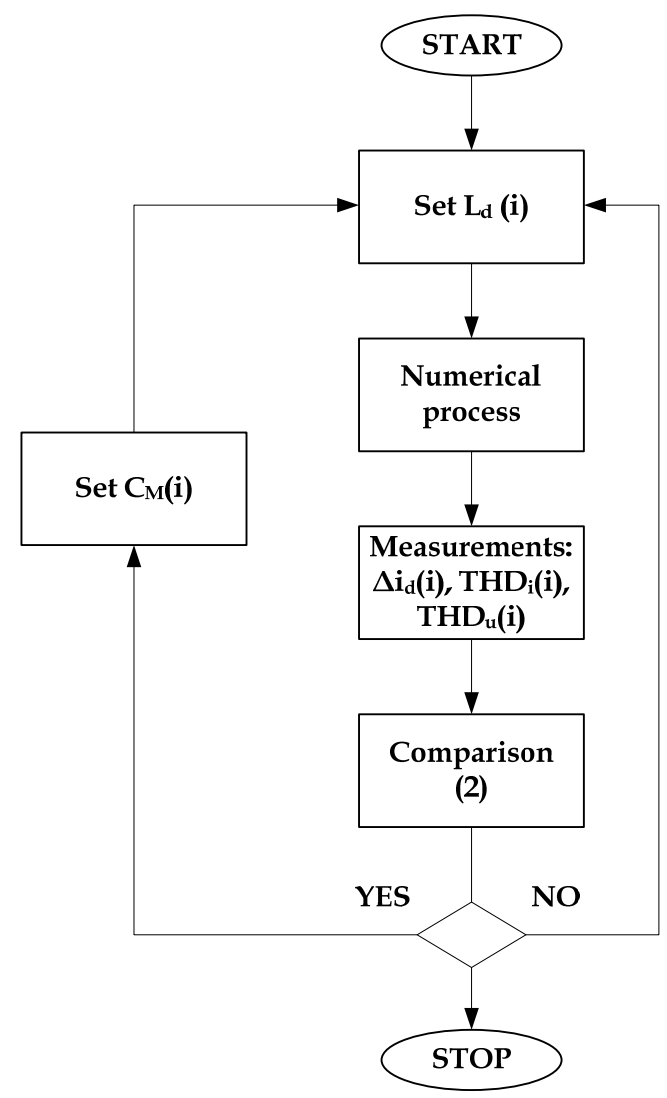

Figure 3. The iteration algorithm for selection of the inductor $\mathrm{Ld}$ an capacitors $\mathrm{CM}_{\mathrm{M}}$ 


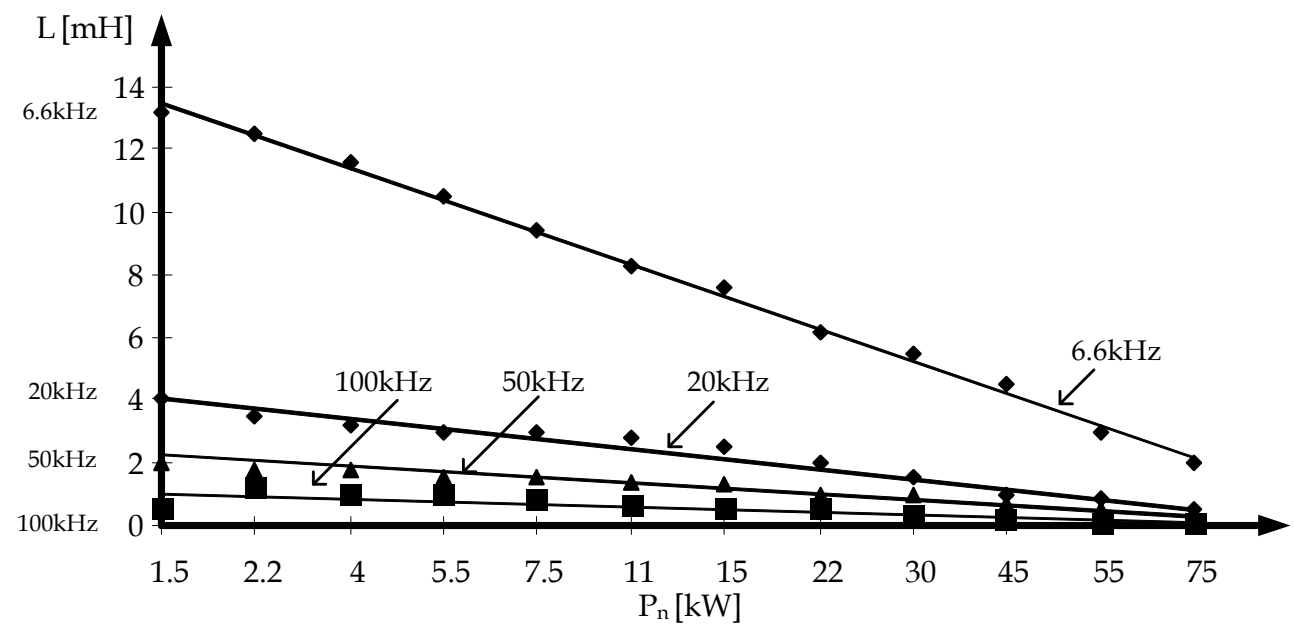

Figure 4. Inductor inductance from iteration algorithm, where $P_{n}[k W]$ is nominal machine power for different transistors switching frequency $[\mathrm{kHz}]$

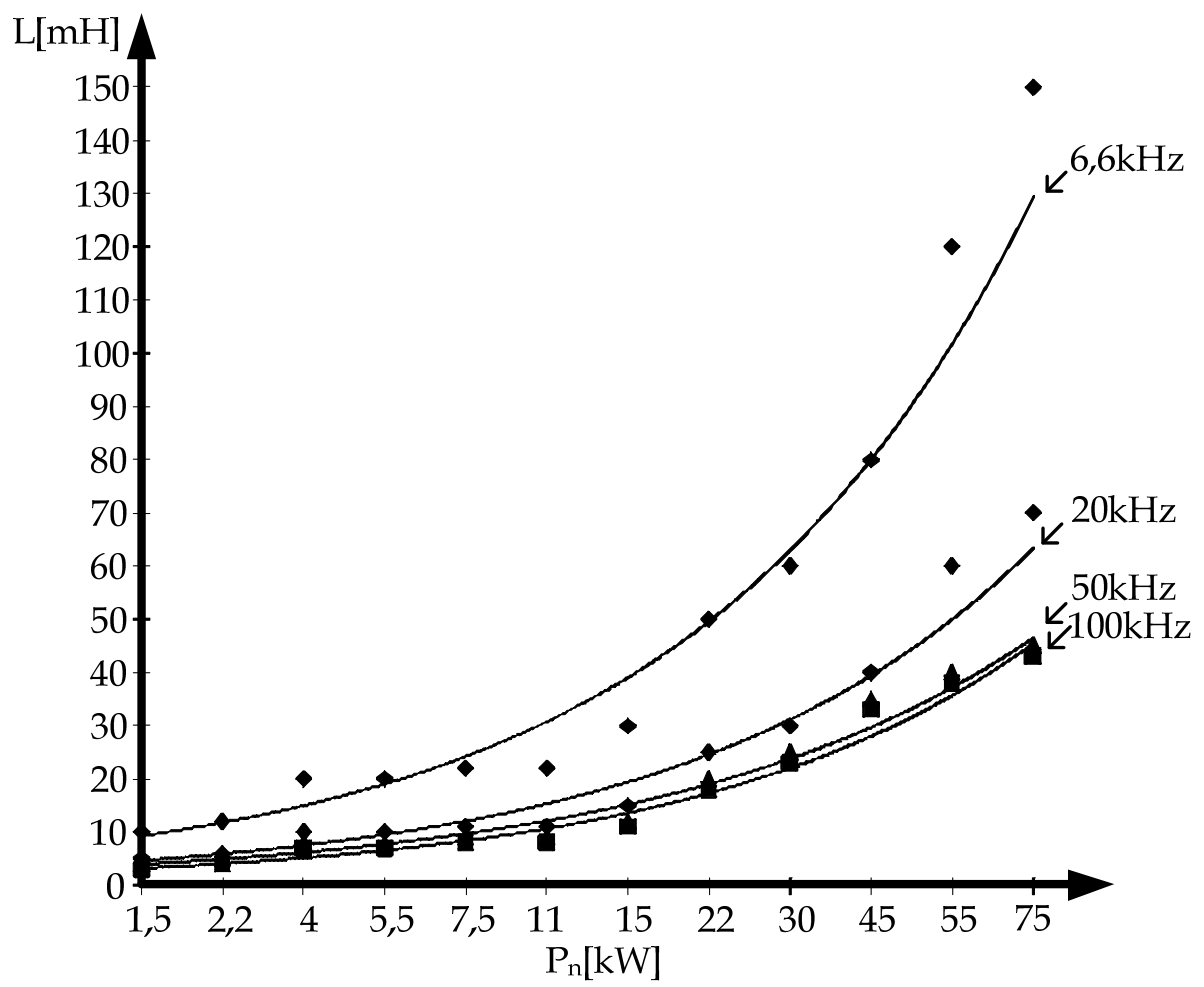

Figure 5. Capacitor capacitance from iteration algorithm where $\mathrm{P}_{\mathrm{n}}[\mathrm{kW}]$ is nominal machine power for different transistors switching frequency $[\mathrm{kHz}]$ 
The value of AC side capacitors $C_{L}$ ought to be about $25 \%$ higher than for $C_{M}$ because of higher harmonics in supply network voltage:

$$
C_{L} \approx 1,25 \cdot C_{M}
$$

\begin{tabular}{|c|c|c|c|c|c|c|c|}
\hline $\mathbf{P}_{\mathbf{n}}[\mathrm{kW}]$ & $\mathbf{L d}_{\mathbf{d}}[\mathrm{mH}]$ & $\mathbf{C}_{\mathbf{M}}[\mu \mathrm{F}]$ & $\mathbf{C}_{\mathrm{L}}[\mu \mathrm{F}]$ & $\mathbf{P}_{\mathbf{n}}[\mathrm{kW}]$ & $\mathbf{L d}_{\mathbf{d}}[\mathrm{mH}]$ & $\mathbf{C}_{\mathbf{M}}[\mu \mathrm{F}]$ & $\mathbf{C}_{\mathrm{L}}[\mu \mathrm{F}]$ \\
\hline 1,5 & 13,2 & 10 & 10 & 15 & 7,6 & 30 & 35 \\
\hline 2,2 & 12,5 & 12 & 12 & 22 & 6,2 & 50 & 60 \\
\hline 4 & 11,6 & 20 & 20 & 30 & 5,5 & 60 & 70 \\
\hline 5,5 & 10,5 & 20 & 20 & 45 & 4,5 & 80 & 90 \\
\hline 7,5 & 9,4 & 22 & 22 & 55 & 3 & 120 & 150 \\
\hline 11 & 8,3 & 22 & 25 & 75 & 2 & 150 & 200 \\
\hline
\end{tabular}

Table 1. Estimated a CSC parameters

\section{The mathematical model of IM supplied by CSC}

\subsection{Introduction to mathematical model}

Differential equation for the dc-link is as follows

$$
e_{d}=i_{d} R_{d}+L_{d} \frac{d i_{d}}{d \tau}+u_{d}
$$

where: $\mathrm{ud}_{\mathrm{d}}$ is the inverter input voltage, $\mathrm{R}_{\mathrm{d}}$ is the inductor resistance, $\mathrm{Ld}$ is the inductance, $\mathrm{ed}_{\mathrm{d}}$ is the control voltage in dc-link, id is the current in dc-link.

Equation (4) is used together with differential equation for the induction motor to derive the models of induction motor fed by the CSI.

The model of a squirrel-cage induction motor expressed as a set of differential equations for the stator-current and rotor-flux vector components presented in $\alpha \beta$ stationary coordinate system is as follows [Krzeminski Z., 1987]:

$$
\begin{gathered}
\frac{d i_{s \alpha}}{d \tau}=-\frac{R_{s} L_{r}^{2}+R_{r} L_{m}^{2}}{L_{r} w_{\sigma}} i_{s \alpha}+\frac{R_{r} L_{m}}{L_{r} w_{\sigma}} \psi_{r \alpha}+\omega_{r} \frac{L_{m}}{w_{\sigma}} \psi_{r \beta}+\frac{L_{r}}{w_{\sigma}} u_{s \alpha}, \\
\frac{d i_{s \beta}}{d \tau}=-\frac{R_{s} L_{r}^{2}+R_{r} L_{m}^{2}}{L_{r} w_{\sigma}} i_{s \beta}+\frac{R_{r} L_{m}}{L_{r} w_{\sigma}} \psi_{r \beta}-\omega_{r} \frac{L_{m}}{w_{\sigma}} \psi_{r \alpha}+\frac{L_{r}}{w_{\sigma}} u_{s \beta}, \\
\frac{d \psi_{r \alpha}}{d \tau}=-\frac{R_{r}}{L_{r}} \psi_{r \alpha}-\omega_{r} \psi_{r \beta}+\frac{R_{r} L_{m}}{L_{r}} i_{s \alpha}, \\
\frac{d \psi_{r \beta}}{d \tau}=-\frac{R_{r}}{L_{r}} \psi_{r \beta}+\omega_{r} \psi_{r \alpha}+\frac{R_{r} L_{m}}{L_{r}} i_{s \beta},
\end{gathered}
$$




$$
\frac{d \omega_{r}}{d \tau}=\frac{L_{m}}{J L_{r}}\left(\psi_{r \alpha} i_{s \beta}-\psi_{r \beta} i_{s \alpha}\right)-\frac{1}{J} m_{0}
$$

where

$R_{r}, R_{s}$ are the motor windings resistance, $L_{s}, L_{r}, L m$ are stator, rotor and mutual inductance, $\mathrm{u}_{\mathrm{s} \alpha}, \mathrm{u}_{\mathrm{s} \beta}, \mathrm{i}_{\mathrm{s} \alpha}, \mathrm{i}_{\mathrm{s} \beta}, \psi_{\mathrm{r} \alpha}, \psi_{\mathrm{r} \beta}$ are components of stator voltage, currents and rotor flux vectors, $\omega_{\mathrm{r}}$ is the angular rotor velocity, $\mathrm{J}$ is the torque of inertia, $\mathrm{m}$ o is the load torque. All variables and parameters are in $\mathrm{p} . \mathrm{u}$.

\subsection{The mathematical model of IM contains full drive system equations}

The vector components of the rotor flux together with inverter output current are used to derive model of IM fed by the CSI. The model is developed using rotating reference frame $x y$ with $x$ axis orientated with output current vector. The $y$ component of the output current vector is equal to zero.

The variables in the rotating reference frame are presented in Fig. 6.

The output current under assumption an ideal commutator can be expressed

$$
i_{f}=K \cdot i_{d}
$$

where

$\mathrm{K}$ is the unitary commutation function $(\mathrm{K}=1)$.

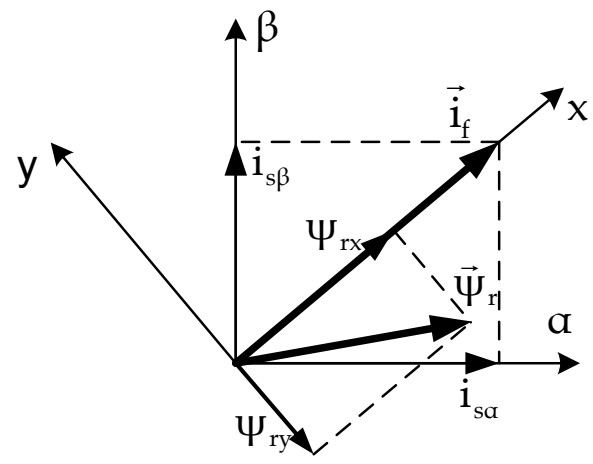

Figure 6. Variables in the rotating frame of references

If the commutation function is $\mathrm{K}=1$ than

$$
\left|i_{f}\right| \approx i_{d}
$$

The equation (12) results from (11) taking into account ideal commutator of the CSI, according to equation 


$$
\begin{aligned}
& p_{D \text { Clink }}=p_{A C \text { motor side }}, \\
& u_{d} i_{d}=u_{s x} i_{f x}
\end{aligned}
$$

where: $\mathrm{u}_{\mathrm{d}}$ is the input six transistors bridge voltage, $\mathrm{u}_{\mathrm{sx}}$ is the stator voltage component.

The full model of the drive system in rotating reference frame $x y$ with $\mathrm{x}$ axis oriented with inverter output current vector is as follows

$$
\begin{gathered}
\frac{d i_{s x}}{d \tau}=-\frac{R_{s} L_{r}^{2}+R_{r} L_{m}^{2}}{L_{r} w_{\sigma}} i_{s x}+\frac{R_{r} L_{m}}{L_{r} w_{\sigma}} \psi_{r x}+\omega_{i} i_{s y}+\omega_{r} \frac{L_{m}}{w_{\sigma}} \psi_{r y}+\frac{L_{r}}{w_{\sigma}} u_{s x}, \\
\frac{d i_{s y}}{d \tau}=-\frac{R_{s} L_{r}^{2}+R_{r} L_{m}^{2}}{L_{r} w_{\sigma}} i_{s y}+\frac{R_{r} L_{m}}{L_{r} w_{\sigma}} \psi_{r y}-\omega_{i} i_{s x}-\omega_{r} \frac{L_{m}}{w_{\sigma}} \psi_{r x}+\frac{L_{r}}{w_{\sigma}} u_{s y^{\prime}} \\
\frac{d \psi_{r x}}{d \tau}=-\frac{R_{r}}{L_{r}} \psi_{r x}+\left(\omega_{i}-\omega_{r}\right) \psi_{r y}+\frac{R_{r} L_{m}}{L_{r}} i_{s x^{\prime}}, \\
\frac{d \psi_{r y}}{d \tau}=-\frac{R_{r}}{L_{r}} \psi_{r y}-\left(\omega_{i}-\omega_{r}\right) \psi_{r x}+\frac{R_{r} L_{m}}{L_{r}} i_{s y}, \\
\frac{d \omega_{r}}{d \tau}=\frac{L_{m}}{J L_{r}}\left(\psi_{r x} i_{s y}-\psi_{r y} i_{s x}\right)-\frac{1}{J} m_{0}, \\
\frac{d i_{d}}{d \tau}=\frac{e_{d}}{L_{d}}-\frac{R_{d}}{L_{d}} i_{d}-\frac{u_{s x}}{L_{d}}, \\
\frac{d u_{s x}}{d \tau}=\frac{1}{C_{M}}\left(i_{f x}-i_{s x}\right)+\omega_{i} u_{s y}, \\
\frac{d u_{s y}}{d \tau}=-\frac{1}{C_{M}} i_{s y}-\omega_{i} u_{s x} .
\end{gathered}
$$

where: $\omega_{\mathrm{i}}$ is angular frequency of vector $\vec{i}_{f}, \mathrm{i}_{\mathrm{sx}}, \mathrm{i}_{\text {sy }}$ are the capacitors currents.

\section{The nonlinear multi-scalar voltage control of IM with PI controllers}

\subsection{The simplified Multi-scalar control}

The Nonlinear multi-scalar control was presented by authors [Krzeminski Z., 1987, Glab (Morawiec) M. et. al., 2005, 2007]. This control in classical form based on PI controllers. The simplify multi-scalar control of IM supplied by CSC for different vector components $\left(\vec{\psi}_{r}, \vec{i}_{s}\right)$, $\left(\vec{\psi}_{s}, \vec{i}_{s}\right),\left(\vec{\psi}_{m}, \vec{i}_{s}\right)$ was presented in [Glab (Morawiec) M. et. al., 2005, 2007]. These multi-scalar 
control structures give different dynamical and statical properties of IM supplied by CSI. In this chapter the simplified control is presented. The simplification is based on (11) and (12) equations. If the capacity $\mathrm{C}_{\mathrm{M}}$ has small values (a few $\mu \mathrm{F}$ ) the mathematical equations (19) (20) can be ommitted and the output current vector in stationary state is $\left|i_{f}\right| \approx\left|i_{s}\right|$. Under this simplification, to achieve the decoupling between two control paths the multi-scalar model based control system was proposed [Krzeminski Z., 1987, Glab (Morawiec) M. et. al., $2005,2007]$. The variables for the multi-scalar model of IM are defined

$$
\begin{gathered}
x_{11}=\omega_{r}, \\
x_{12}=-i_{d} \psi_{r y}, \\
x_{21}=\psi_{r x}^{2}+\psi_{r y}^{2}, \\
x_{22}=i_{d} \psi_{r x},
\end{gathered}
$$

where

$\mathrm{x}_{11}$ is the rotor speed, $\mathrm{x}_{12}$ is the variable proportional to electromagnetic torque, $\mathrm{x}_{21}$ is the square of rotor flux and $\mathrm{x}_{22}$ is the variable named magnetized variable [Krzeminski, 1987].

Assumption of such machine state variables may lead to improvement of the control system quality due to the fact that e.g. the $\mathrm{x}_{12}$ variable is directly the electromagnetic torque of the machine. In FOC control methods [Klonne A. \& Fuchs W.F., 2003, 2004, Salo M. \& Tuusa H. 2004] the electromagnetic torque is not directly but indirectly controlled (the isq stator current component). With the assumption of a constant rotor flux modulus, such a control conception is correct. The inaccuracy of the machine parameters, asymmetry or inadequately aligned control system may lead to couplings between control circuits.

The mathematical model for new state of variables (21) - (24) used (15) - (18) is expressed by differential equations:

$$
\begin{gathered}
\frac{d x_{11}}{d \tau}=\frac{L_{m}}{J L_{r}}\left(x_{12}\right)-\frac{1}{J} m_{0} \\
\frac{d x_{12}}{d \tau}=-\frac{1}{T_{i}} x_{12}+\frac{1}{L_{d}} u_{s x} \psi_{r y}-\frac{R_{r} L_{m}}{L_{r}} i_{s y} i_{d}+v_{1}, \\
\frac{d x_{21}}{d \tau}=-2 \frac{R_{r}}{L_{r}} x_{21}+2 R_{r} \frac{L_{m}}{L_{r}} x_{22} \\
\frac{d x_{22}}{d \tau}=-\frac{1}{T_{i}} x_{22}+\frac{R_{r} L_{m}}{L_{r}} i_{s x} i_{d}+v_{2} .
\end{gathered}
$$


The compensation of nonlinearities in differential equation leads to the following expressions for control variables $\mathrm{v} 1$ and $\mathrm{v} 2$ appearing in differential equations (27) - (28):

$$
\begin{aligned}
& v_{1}=\frac{R_{r} L_{m}}{L_{r}} i_{s y} i_{d}-\frac{u_{s x}}{L_{d}} \cdot \psi_{r y}+\frac{1}{T_{i}} m_{1}, \\
& v_{2}=-\frac{R_{r} L_{m}}{L_{r}} i_{s x} i_{d}+\frac{u_{s x}}{L_{d}} \cdot \psi_{r x}+\frac{1}{T_{i}} m_{2},
\end{aligned}
$$

where $\mathrm{m}_{1,2}$ are the PI controllers output and

$$
\frac{1}{T_{i}}=\frac{R_{s}}{L_{r}}+\frac{R_{d}}{L_{d}} .
$$

The control variables are specified

$$
\begin{aligned}
& e_{d}=-L_{d} \cdot \frac{\psi_{r y} v_{1}-\psi_{r x} v_{2}}{x_{21}}, \\
& \omega_{i}=\frac{\psi_{r x} v_{1}+\psi_{r y} v_{2}}{i_{d} \cdot x_{21}}+x_{11},
\end{aligned}
$$

when $x_{21}, \mathrm{i}_{\mathrm{d}} \neq 0$.

The inverter control variables are: voltage ed and the output current vector pulsation. The multi-scalar control of IM supplied by CSI was named voltage control because the control variable is voltage ed in dc-link.

The decoupled two subsystems are obtained:

- $\quad$ electromagnetic subsystem

$$
\begin{gathered}
\frac{d x_{21}}{d \tau}=-2 \frac{R_{r}}{L_{r}} x_{21}+2 \frac{R_{r} L_{m}}{L_{r}} x_{22}, \\
\frac{d x_{22}}{d \tau}=\frac{1}{T_{i}}\left(-x_{22}+m_{2}\right),
\end{gathered}
$$

- $\quad$ electromechanical subsystem

$$
\begin{aligned}
& \frac{d x_{11}}{d \tau}=\frac{L_{m}}{J L_{r}} x_{12}-\frac{1}{J} m_{0}, \\
& \frac{d x_{12}}{d \tau}=\frac{1}{T_{i}}\left(-x_{12}+m_{1}\right) .
\end{aligned}
$$




\subsection{The multi-scalar control with inverter mathematical model}

The author in [Morawiec M., 2007] revealed stability proof of simplified multi-scalar control while the parameters of the CSI are optimal selected.

When the capacitance $\mathrm{C}_{M}$ is neglected the stator current vector $\vec{i}_{S}$ is about $\sim 5 \%$ out of phase to $\vec{i}_{f}$ while nominal torque is set. Then the control variables and decoupling are not obtained precisely. The error is small than $2 \%$ because PI controllers improved it.

In order to compensate these errors the capacity $\mathrm{C}_{\mathrm{M}}$ to mathematical model is applied.

From (19) - (20) in stationary state lead to dependences:

$$
\begin{gathered}
i_{s x}=i_{f x}+\omega_{i f} C_{M} u_{s y}, \\
i_{s y}=-\omega_{i f} C_{M} u_{s x} .
\end{gathered}
$$

The new mathematical model of the drive system is obtained from (38) - (39) through differentiation it and used (15) - (16) in $x y$ coordinate system:

$$
\begin{gathered}
\frac{d i_{s x}}{d \tau}=-\frac{R_{d}}{L_{d}} i_{d}+\frac{1}{L_{d}} e_{d}-\frac{1}{L_{d}} u_{x}-\omega_{i f} C_{M} i_{s y}-\omega_{i f}^{2} C_{M}^{2} u_{s x}, \\
\frac{d i_{s y}}{d \tau}=-\omega_{i f} C_{M} i_{d}+\omega_{i f} C_{M} i_{s x}-\omega_{i f}^{2} C_{M}^{2} u_{s y}, \\
\frac{d \psi_{r x}}{d \tau}=-\frac{R_{r}}{L_{r}} \psi_{r x}+\left(\omega_{i f}-\omega_{r}\right) \psi_{r y}+\frac{R_{r} L_{m}}{L_{r}} i_{s x}, \\
\frac{d \psi_{r y}}{d \tau}=-\frac{R_{r}}{L_{r}} \psi_{r y}-\left(\omega_{i f}-\omega_{r}\right) \psi_{r x}+\frac{R_{r} L_{m}}{L_{r}} i_{s y}, \\
\frac{d i_{d}}{d \tau}=-\frac{R_{d}}{L_{d}} i_{d}+\frac{1}{L_{d}} e_{d}-\frac{1}{L_{d}} u_{s x}, \\
\frac{d u_{s x}}{d \tau}=\frac{1}{C_{M}}\left(i_{f x}-i_{s x}\right)+\omega_{i f} u_{s y}, \\
\frac{d u_{s y}}{d \tau}=-\frac{1}{C_{M}} i_{s y}-\omega_{i f} u_{s x} .
\end{gathered}
$$

Substituting (38) - (39) to multi-scalar variables [Krzeminski Z., 1987] one obtains:

$$
x_{11}=\omega_{r}
$$




$$
\begin{gathered}
x_{12}=-i_{f x} \psi_{r y}-\omega_{i f} C_{M} x_{32}, \\
x_{21}=\psi_{r x}^{2}+\psi_{r y}^{2}, \\
x_{22}=i_{f x} \psi_{r x}+\omega_{i f} C_{M} x_{31}
\end{gathered}
$$

and

$$
\begin{aligned}
& x_{31}=\psi_{r x} u_{s y}-\psi_{r y} u_{s x}, \\
& x_{32}=\psi_{r x} u_{s x}+\psi_{r y} u_{s y} .
\end{aligned}
$$

The multi-scalar model for new multi-scalar variables has the form:

$$
\begin{gathered}
\frac{d x_{11}}{d \tau}=\frac{L_{m}}{J L_{r}} x_{12}-\frac{1}{J} m_{0}, \\
\frac{d x_{12}}{d \tau}=-\frac{1}{T_{i}} x_{12}+\frac{1}{L_{d}} u_{s x} \psi_{r y}-x_{11} x_{22}+v_{1}, \\
\frac{d x_{21}}{d \tau}=-2 \frac{R_{r}}{L_{r}} x_{21}+2 R_{r} \frac{L_{m}}{L_{r}} x_{22}, \\
\frac{d x_{22}}{d \tau}=-\frac{1}{T_{i}} x_{22}-\frac{1}{L_{d}} u_{s x} \psi_{r x}+\frac{R_{r} L_{m}}{L_{r}} i_{d}^{2}+x_{11} x_{12}+v_{2},
\end{gathered}
$$

where

$$
\begin{gathered}
v_{1}=-\frac{1}{L_{d}} e_{d} \psi_{r y}+\omega_{i f}\left(x_{22}-\frac{R_{d}}{L} C_{M} x_{32}-C_{M} \frac{R_{r} L_{m}}{L_{r}} p_{s}\right), \\
v_{2}=\frac{1}{L_{d}} e_{d} \psi_{r x}+\omega_{i f}\left(-x_{12}+\frac{R_{d}}{L} C_{M} x_{31}+C_{M} \frac{R_{r} L_{m}}{L_{r}} q_{s}\right), \\
q_{s}=i_{s x} u_{s y}-i_{s y} u_{s x}, \\
p_{s}=u_{s x} i_{s x}+u_{s y} i_{s y} .
\end{gathered}
$$

The compensation of nonlinearities in differentials equation leads to the following expressions for control variables v1 and v2 appearing in differential equations (54), (56):

$$
v_{1}=\frac{1}{T_{i}} m_{1}-\frac{1}{L_{d}} u_{s x} \psi_{r y}+x_{11} x_{22}
$$




$$
v_{2}=\frac{1}{T_{i}} m_{2}+\frac{1}{L_{d}} u_{s x} \psi_{r x}-x_{11} x_{12}-\frac{R_{r} L_{m}}{L_{r}} i_{d}^{2}
$$

and the control variables

$$
\begin{gathered}
e_{d}=L_{d} \frac{V_{2} x_{41}-V_{1} x_{42}}{\psi_{r x} x_{41}+\psi_{r y} x_{42}}, \\
\omega_{i}=\frac{V_{1} \psi_{r x}+V_{2} \psi_{r y}}{\psi_{r x} x_{41}+\psi_{r y} x_{42}},
\end{gathered}
$$

where

$$
\begin{aligned}
& x_{41}=x_{22}-\frac{R_{d}}{L} C_{M} x_{32}-C_{M} \frac{R_{r} L_{m}}{L_{r}} p_{s}, \\
& x_{42}=-x_{12}+\frac{R_{d}}{L} C_{M} x_{31}+C_{M} \frac{R_{r} L_{m}}{L_{r}} q_{s},
\end{aligned}
$$

$\frac{1}{T_{i}}$ is determined in (31).

The decoupled two subsystems are obtained as in (34) - (37).

\subsection{The multi-scalar adaptive-backstepping control of an IM supplied by the CSI}

The backstepping control can be appropriately written for an induction squirrel-cage machine supplied from a VSI. In literature the backstepping control is known for adaptation of selected machine parameters, written for an induction motor [Tan H. \& Chang J., 1999, Young Ho Hwang, 2008]. In [Tan H. \& Chang J., 1999, Young Ho Hwang, 2008] the authors defined the machine state variables in the dq coordinate system, oriented in accordance with the rotor flux vector (FOC). The control method presented in [Tan H. \& Chang J., 1999, Young Ho Hwang, 2008] is based on control of the motor state variables: $\omega_{\mathrm{r}}$ - rotor angular speed, rotor flux modulus and the stator current vector components: isd and isq. Selection of the new motor state variables, as in the case of multi-scalar control with linear PI regulators, leads to a different form of expressions describing the machine control and decoupling. The following state variables have been selected for the multi-scalar backstepping control

$$
\begin{aligned}
& e_{1}=x_{11}^{*}-x_{11}, \\
& e_{2}=x_{12}^{*}-x_{12}, \\
& e_{3}=x_{21}^{*}-x_{21},
\end{aligned}
$$




$$
e_{4}=\left(2 R_{r} \frac{L_{m}}{L_{r}} x_{22}\right)^{*}-2 R_{r} \frac{L_{m}}{L_{r}} x_{22},
$$

where: $x_{11}, x_{12}, x_{21}$ and $x_{22}$ are defined in (47) - (50).

The e 4 tracking error is defined in (70), it does not influence on the control system properties and is only an accepted simplification in the format of decoupling variables.

Derivatives of the (67) - (70) errors take the form

$$
\begin{gathered}
\dot{e}_{1}=\frac{L_{m}}{J L_{r}} e_{2}-k_{1} e_{1}-\frac{\tilde{m}_{0}}{J}, \\
\dot{e}_{2}=k_{1} e_{2}-k_{1}^{2} \frac{J L_{r}}{L_{m}} e_{1}+\frac{L_{r}}{L_{m}} \dot{\hat{m}}_{0}+\frac{1}{T_{i}} x_{12}-\frac{1}{L_{d}} u_{s x} \psi_{r y}+x_{11} x_{22}+\frac{R_{r} L_{m}}{L_{r}} i_{s y} i_{d}-v_{1}, \\
\dot{e}_{3}=-k_{3} e_{3}+e_{4}, \\
\dot{e}_{4}=-k_{3}^{2} e_{3}+k_{3} e_{4}-4\left(\frac{R_{r}}{L_{r}}\right)^{2} x_{21}+4\left(\frac{R_{r}}{L_{r}}\right)^{2} L_{m} x_{22}+2 \frac{R_{r} L_{m}}{L_{r} T_{i}} x_{22}+2 \frac{R_{r} L_{m}}{L_{r} L_{d}} u_{s x} \psi_{r x}-2\left(\frac{R_{r} L_{m}}{L_{r}}\right)^{2} i_{s x} i_{d}+ \\
-2 \frac{R_{r} L_{m}}{L_{r}} x_{11} x_{12}-2 \frac{R_{r} L_{m}}{L_{r}} v_{2}
\end{gathered}
$$

The Lyapunov function derivative, with (71) - (74) taken into account, may be expressed as:

$$
\begin{aligned}
\dot{V} & =-k_{1}^{2} e_{1}-k_{2}^{2} e_{2}-k_{3}^{2} e_{3}-k_{4}^{2} e_{4}+e_{2}\left(f_{1}-v_{1}\right)+e_{4}\left(f_{2}-a_{3} v_{2}\right)+ \\
& +\tilde{m}_{0}\left(-\frac{e_{1}}{J}-k_{1} \frac{L_{r}}{L_{m}} e_{2}+\frac{\dot{\hat{m}}_{0}}{\gamma}\right)
\end{aligned}
$$

where

$$
\begin{gathered}
v_{1}=-\frac{1}{L_{d}} e_{d} \psi_{r y}+\omega_{i f} x_{41}, \\
v_{2}=\frac{1}{L_{d}} e_{d} \psi_{r x}+\omega_{i f} x_{42}^{\prime} \\
f_{1}=\lim i t_{12} \cdot e_{1}\left(\frac{L_{m}}{J L_{r}}-k_{1}^{2} \frac{J L_{r}}{L_{m}}\right)+k_{2} e_{2}+k_{1} e_{2}+\frac{L_{r}}{L_{m}} \dot{\hat{m}}_{0}+\frac{1}{T_{i}} x_{12}-\frac{1}{L_{d}} u_{s x} \psi_{r y}+ \\
+x_{11} x_{22} \\
f_{2}=\lim i t_{12} \cdot\left(e_{3}-k_{3}^{2} e_{3}\right)+k_{4} e_{4}+k_{3} e_{4}-4\left(\frac{R_{r}}{L_{r}}\right)^{2} x_{21}+4\left(\frac{R_{r}}{L_{r}}\right)^{2} L_{m} x_{22}+2 \frac{R_{r} L_{m}}{L_{r} T_{i}} x_{22}+ \\
+2 \frac{R_{r} L_{m}}{L_{r} L_{d}} u_{s x} \psi_{r x}-2\left(\frac{R_{r} L_{m}}{L_{r}}\right)^{2} i_{d}^{2}-2 \frac{R_{r} L_{m}}{L_{r}} x_{11} x_{12}
\end{gathered}
$$




$$
a_{3}=2 \frac{R_{r} L_{m}}{L_{r}} .
$$

limit12 - is a dynamic limitation in the motor speed control subsystem,

$\operatorname{limit}_{22}$ - is a dynamic limitation in the rotor flux control subsystem,

$\mathrm{k}_{1} \ldots \mathrm{k}_{4}$ and $\gamma$ are the constant gains.

The control variables take the form:

$$
\begin{gathered}
e_{d}=L_{d} \frac{x_{41} f_{2}-a_{3} x_{42} f_{1}}{a_{3}\left(\psi_{r x} x_{41}+\psi_{r y} x_{42}\right)}, \\
\omega_{i}=\frac{a_{3} \psi_{r x} f_{1}+\psi_{r y} f_{2}}{a_{3}\left(\psi_{r x} x_{41}+\psi_{r y} x_{42}\right)} .
\end{gathered}
$$

The inverter control variables are: voltage ed and the output current vector pulsation. The two decoupled subsystems are obtained as in (34) - (37).

The load torque mo can be estimated from the formula:

$$
\dot{\hat{m}}_{0}=\gamma\left(\frac{e_{1}}{J}+k_{1} \frac{L_{r}}{L_{m}} e_{2}\right) .
$$

\subsection{Dynamic limitations of the reference variables}

In control systems with the conventional linear controllers of the PI or PID type, the reference (or controller output) variable dynamics are limited to a constant value or dynamically changed by (83) - (84), depending on the drive working point.

Control systems where the control variables are determined from the Lyapunov function (like in backstepping control) have no limitations in the set variable control circuits. The reference variable dynamics may be limited by means of additional first order inertia elements (e.g. on the set speed signal).

The author of this paper has not come across a solution of the problem in the most significant backstepping control literature references, e.g. [Tan H. \& Chang J., 1999, Young Ho Hwang, 2008]. In the quoted reference positions, the authors propose the use of an inertia elements on the set variable signals. Such approach is an intermediate method, not giving any rational control effects. The use of an inertia element on the reference signal, e.g. of the rotor angular speed, will slow down the reference electromagnetic torque reaction in proportion to the inertia element time-constant. In effect a "slow" build-up of the motor electromagnetic torque is obtained, which may be acceptable in some applications. In practice the aim is to limit the electromagnetic torque value without an impact on the buildup dynamics. Control systems with the Lyapunov function-based control without limitation 
of the set variables are not suitable for direct adaptation in the drive systems. Therefore, a solution often quoted in literature is the use of a PI or PID speed controller at the torque control circuit input.

The set values of the $x_{12}^{*}, x_{22}^{*}$ variables appearing in the e2 and $\mathrm{e}_{4}$ deviations can be dynamically limited and the dynamic limitations are defined by the expressions [Adamowicz M.; Guzinski J., 2005]:

$$
\begin{gathered}
x_{12 \lim }=\sqrt{I_{s \max }^{2} x_{21}-x_{22}^{2}}, \\
x_{22 \lim }=f\left(U_{s \max }^{2}, I_{s \max }^{2}, x_{11}\right),
\end{gathered}
$$

where

$\mathrm{x} 12 \mathrm{lim}$ - the set torque limitation,

$\mathrm{x}_{22 \mathrm{lim}}$ - the $\mathrm{x} 22$ variable limitation,

$I_{\text {smax }}$ - maximum value of the stator current modulus,

$\mathrm{U}_{\mathrm{smax}}$ - maximum value of the stator voltage modulus.

The above given expressions may be modified to:

$$
x_{12 \lim }=\sqrt{I_{s \max }^{2} x_{21}-\frac{x_{21}^{2}}{L_{m}^{2}}},
$$

giving the relationship between the $x_{21}$ variable, the stator current modulus Ismax, and the motor set torque limitation.

For the multi-scalar backstepping control, to the $f_{1}$ and $f_{2}$ variables the limit 12 and limit 22 variables were introduced; they assume the 0 or 1 value depending on the need of limiting the set variable.

Limitation of variables in the Lyapunov function-based control systems may be performed in the following way:

$$
\begin{aligned}
& \text { if }\left(\mathrm{x}_{12}^{*}>\mathrm{x}_{12 \mathrm{lim}}\right) \text { then }\left\{\begin{array}{l}
\text { limit } \\
\mathrm{e}_{2}=\mathrm{x}_{12 \mathrm{lim}}-\mathrm{x}_{12}
\end{array}\right\} \text {, } \\
& \text { if }\left(\mathrm{x}_{12}^{*}<-\mathrm{x}_{12 \mathrm{lim}}\right) \text { then }\left\{\begin{array}{l}
\text { limit } \\
\mathrm{e}_{2}=-\mathrm{x}_{12 \mathrm{lim}}-\mathrm{x}_{12}
\end{array}\right\} \text {, } \\
& \text { else limit }{ }_{12}=1, \\
& \text { if }\left(\mathrm{x}_{22}^{*}>\mathrm{x}_{22 \mathrm{lim}}\right) \text { then }\left\{\begin{array}{l}
\text { limit }_{22}=0, \\
\mathrm{e}_{4}=\mathrm{x}_{22 \mathrm{lim}}-\mathrm{x}_{22}
\end{array}\right\},
\end{aligned}
$$




$$
\begin{gathered}
\text { if }\left(x_{22}^{*}<-x_{22 \lim }\right) \text { then }\left\{\begin{array}{l}
\text { limit }_{22}=0, \\
e_{4}=-x_{22 \lim }-x_{22}
\end{array}\right\} \text {, } \\
\text { else limit } 22=1
\end{gathered}
$$

The dynamic limitations effected in accordance with expressions (83) - (84) limit properly the value of $x_{12}^{*}$ and $x_{22}^{*}$ variables without any interference in the reference signal build-up dynamics.

Fig. 7 presents the variable simulation diagrams. The backstepping control dynamic limitations were used.

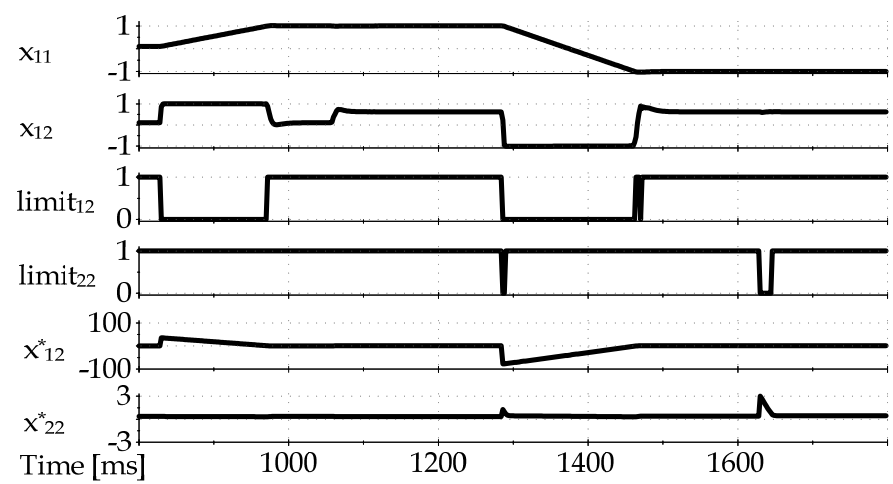

Figure 7. Diagrams of multi-scalar variables in the machine dynamic states, the $\mathrm{x}_{12} \mathrm{ogr}=1.0$ and $\mathrm{x} 22 \mathrm{ogr}=$ 0.74 limitations were set for a drive system with an induction squirrel-cage machine supplied from a CSC-simulation diagrams, $x^{*} 12$ - diagram of the machine set electromagnetic torque (without signal limitation), $x^{*} 22$ - diagram of the $x^{*} 22$ set signal (without limitation).

\subsection{Impact of the dynamic limitation on the estimation of parameters}

The use of a variable limitation algorithm may have a negative impact on the control system estimated parameters. This has a direct connected with the limited deviation values, which are then used in an adaptive parameter estimation. Such phenomenon is presented in Fig. 7. The estimated parameter in the control system is the motor load torque $\hat{m}_{0}$. The set electromagnetic torque is limited to the $\mathrm{x}_{12 \mathrm{lim}}=1.0$ value. Fig. 7 shows that the estimated load torque increases slowly in the intermediate states. Limitation of the set electromagnetic torque causes the limitation of deviation e2, which in turn causes limited increase dynamics of the estimated load torque. The $\hat{m}_{0}$ value for limiti2 $=0$ in the dynamic states does not reach the real value of the load torque, which should be $\hat{m}_{0} \approx x_{12}$. A large $\tilde{m}_{0}$ estimation error occurs in the intermediate states, which can be seen in Fig. 8. The estimation error in the intermediate states is $\tilde{m}_{0} \neq 0$ because the torque limitation, introduced to the control system, is not compensated. The simulation and experimental tests have shown that the load torque estimation error in the intermediate state has an insignificant impact on the 
speed control. Omitting $\hat{m}_{0}$ in the set torque $x_{12}^{*}$ expression eliminates the intermediate state speed over-regulation. But absence of $\hat{m}_{0}$ in $x^{*} 12$ for a steady state gives the deviation value $e_{1} \neq 0$ and lack of full control over maintaining the rotor set angular speed. Compensation of the limit12 limitation introduced to the control system is possible by installing a corrector in the rotor angular speed control circuit.

A corrector in the form of an e1 signal integrating element was added to the set electromagnetic torque $x^{*} 12$ signal. In this way a system reacting to the change of machine real load torque was obtained. The introduced correction minimizes the rotor angular speed deviation and the corrector signal may be treated as the estimated load torque value.

The correction element is determined by the expression:

$$
K T_{L}=k_{e 1} \int_{t_{k-1}}^{t_{k}} e_{1} d \tau,
$$

where

$t_{k-1} \ldots t_{k}$ is the e1 signal integration range,

$\mathrm{KT}_{\mathrm{L}}$ - correction element,

$k_{e 1}-$ is the correction element amplification.

The gain $\mathrm{k}_{\mathrm{e}}$ should be adjusted that the speed overregulation in the intermediate state does not exceed $5 \%$ :

$$
0<k_{e 1} \leq 0,1 \cdot k_{1}
$$

The correction element amplification must not be greater than $\mathrm{k}_{1}$, or:

$$
k_{e 1} \leq k_{1} \text {. }
$$

For $k_{e 1}>k_{1}$ the $\mathrm{KT}_{\mathrm{L}}$ signal will become an oscillation element and may lead to the control system loss of stability.

The KTL signal must be limited to the x12lim value.

The $\mathrm{x}^{*} 12$ set value expression must be modified:

$$
x_{12}^{*}=\frac{J L_{r}}{L_{m}} k_{1} e_{1}+K T_{L}
$$

where

$$
\hat{m}_{0} \approx K T_{L} .
$$

The use of (93) in the angular speed control circuit improves the load torque estimation and eliminates the steady state speed error. 
Fig. 9 presents the load torque (determined in (94)) estimation as well as $\mathrm{x}_{12}$ and the limit12 limitations.

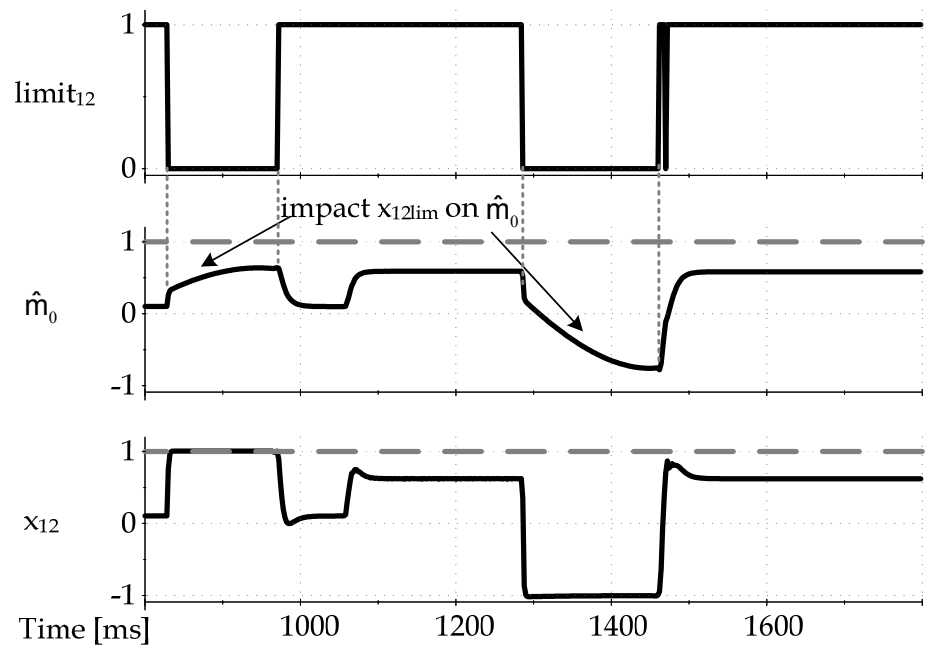

Figure 8. Impact of the electromagnetic torque limitation x12lim on the estimated load torque $\hat{m}_{0}(82)$.
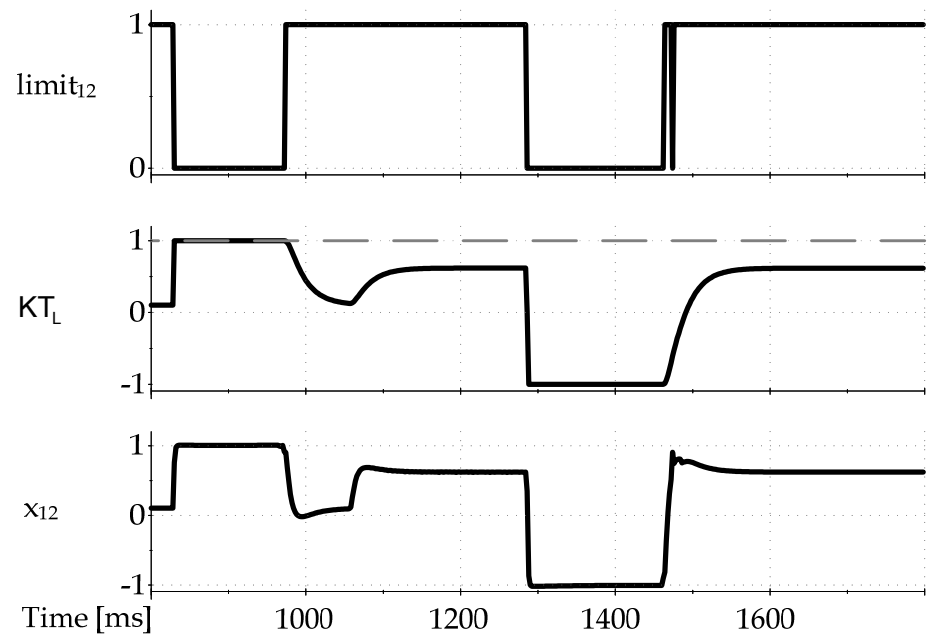

Figure 9. Diagrams of the limit12 variable, $K T_{L}$ load torque and electromagnetic torque $\mathrm{x}_{12 .}$.

\section{The nonlinear multi-scalar current control of induction machine}

Conception of the CSI current control is based on forced components of the CSI output current. The dc-link circuit inductor could be modeled as the first order inertia element with the time constant $\mathrm{T}$ of a value equal to the dc-link circuit time constant value. The dc-link 
equation may be introduced to the induction machine mathematical model to obtain the set CSI output current component. The time constant $\mathrm{T}$ is equal the inductance $\mathrm{Ld}$, it can be written:

$$
\begin{gathered}
\frac{d \overrightarrow{\mathrm{i}}_{s}}{d t}=\frac{1}{T}\left(\overrightarrow{\mathrm{i}}_{f}-\overrightarrow{\mathrm{i}}_{s}\right), \\
T=\frac{R_{d}}{L_{d}} .
\end{gathered}
$$

\subsection{The simplified multi-scalar current control of induction machine}

The simplified version of the CSI output current control it is assumed that the output capacitors have negligibly small capacitance, so their impact on the drive system dynamics is small. Assuming that the cartesian coordinate system, where the mathematical model variables are defined, is associated with the CSI output current vector (which with this simplification is the machine stator current) the mathematical model can be obtained (95) and (42) - (43) equations).

The multi-scalar variables have the form

$$
\begin{gathered}
x_{11}=\omega_{r}, \\
x_{12}=-i_{s x} \psi_{r x}, \\
x_{21}=\psi_{r x}^{2}+\psi_{r y}^{2}, \\
x_{22}=i_{s x} \psi_{r x},
\end{gathered}
$$

where

$i_{s x}$ is treated as the output current vector component and $\left|i_{f}\right| \approx\left|i_{s}\right|$.

For those variables, the multi-scalar model has the form:

$$
\begin{gathered}
\frac{d x_{11}}{d \tau}=\frac{L_{m}}{J L_{r}} x_{12}-\frac{1}{J} m_{0}, \\
\frac{d x_{12}}{d \tau}=-\frac{1}{T_{i}} x_{12}+v_{1}, \\
\frac{d x_{21}}{d \tau}=-2 \frac{R_{r}}{L_{r}} x_{21}-2 \frac{R_{r} L_{m}}{L_{r}} x_{22},
\end{gathered}
$$




$$
\frac{d x_{22}}{d \tau}=-\frac{1}{T_{i}} x_{22}+\frac{R_{r} L_{m}}{L_{r}} i_{d}+v_{2}
$$

Applying the linearization method, the following relations are obtained, where $\mathrm{m}_{1}$ is the subordinated regulator output in the speed control line and $\mathrm{m}_{2}$ is the subordinated regulator output in the flux control line

$$
\begin{gathered}
v_{1}=\frac{1}{T_{i}} m_{1}, \\
v_{2}=\frac{1}{T_{i}} m_{2}-\frac{R_{r} L_{m}}{L_{r}} i_{d} .
\end{gathered}
$$

The control variables are modulus of the CSI output current and the output current vector pulsation, given by the following relations:

$$
\begin{gathered}
\left|\mathrm{i}_{\mathrm{f}}\right|=T \frac{v_{2} \psi_{r x}-v_{1} \psi_{r y}}{x_{21} \psi_{r y}}, \\
\omega_{i}=\frac{v_{1}+v_{2}}{x_{21} i_{s x}}+x_{11} .
\end{gathered}
$$

where: $\mathrm{Ld}$-inductance, $\mathrm{T}_{\mathrm{i}}$ - the system time constant.

\subsection{The multi-scalar current control of induction machine}

The current control analysis presented in the preceding sections does not take the CSI output capacitors into account. Such simplification may be applied because of the small impact of the capacitors upon the control variables (the machine stator current and voltage are measured). The capacitor model will have a positive impact on the control system dynamics.

The output capacitor relations have the form:

$$
\frac{d \overrightarrow{\mathrm{u}}_{s}}{d t}=\frac{1}{C_{M}}\left(\overrightarrow{\mathrm{i}}_{f}-\overrightarrow{\mathrm{i}}_{s}\right)
$$

where: $\overrightarrow{\mathrm{u}}_{s}$ is the capacitor voltage vector, $\overrightarrow{\mathrm{i}}_{f}$ is the current source inverter output current vector, $\overrightarrow{\mathrm{i}}_{s}$ is the stator current vector.

Using the approximation method, relation (38) may be written as follows:

$$
\frac{\overrightarrow{\mathrm{u}}_{s}(k)-\overrightarrow{\mathrm{u}}_{s}(k-1)}{T_{i m p}}=\frac{1}{C_{M}}\left[\overrightarrow{\mathrm{i}}_{f}(k)-\overrightarrow{\mathrm{i}}_{s}(k)\right] .
$$


Deriving $\mathbf{u}_{\mathrm{s}}(\mathrm{k})$ from (38), the motor stator voltage is obtained as a function of the output current, stator current and stator voltage, in the form:

$$
\overrightarrow{\mathrm{u}}_{s}(k)=\frac{T_{i m p}}{C_{M}}\left[\overrightarrow{\mathrm{i}}_{f}(k)-\overrightarrow{\mathrm{i}}_{s}(k)\right]+\overrightarrow{\mathrm{u}}_{s}(k-1),
$$

where

$\overrightarrow{\mathrm{u}}_{s}(k)$ is the stator voltage vector at the $\mathrm{k}$-th moment, Timp - sampling period.

In the equations (5) - (9) representing the cage induction motor mathematical model the stator current vector components are appeared but the direct control variables do not. The motor stator current vector components cannot be the control variables because the multiscalar model relations are derived from them. This is a different situation than with the FOC control. The FOC control is based on the machine stator current components described in a coordinate system associated with the rotor flux and the stator current components are the control variables. Therefore, control variables must be introduced into the mathematical model (5) - (9). The control may be introduced considering the machine currents (5) - (6) and equation (95) written for the $\alpha \beta$ components and describing the dc-link circuit dynamics. Adding the respective sides of equations (5) and (95) and equations (6) and (95), where equation (95) must be written with the $(\alpha \beta)$ components - the mathematical model of the drive system fed by the CSI is obtained:

$$
\begin{aligned}
& \frac{d i_{s \alpha}}{d \tau}=-\frac{R_{s} L_{r}^{2} T+R_{r} L_{m}^{2} T+L_{r} w_{\sigma}}{2 L_{r} w_{\sigma} T} i_{s \alpha}+\frac{R_{r} L_{m}}{2 L_{r} w_{\sigma}} \psi_{r \alpha}+\omega_{r} \frac{L_{m}}{2 w_{\sigma}} \psi_{r \alpha}+\frac{L_{r}}{2 w_{\sigma}} u_{s \alpha}+\frac{1}{2 T} i_{f \alpha}, \\
& \frac{d i_{s \beta}}{d \tau}=-\frac{R_{s} L_{r}^{2} T+R_{r} L_{m}^{2} T+L_{r} w_{\sigma}}{2 L_{r} w_{\sigma} T} i_{s \beta}+\frac{R_{r} L_{m}}{2 L_{r} w_{\sigma}} \psi_{r \beta}-\omega_{r} \frac{L_{m}}{2 w_{\sigma}} \psi_{r \alpha}+\frac{L_{r}}{2 w_{\sigma}} u_{s \beta}+\frac{1}{2 T} i_{f \beta},
\end{aligned}
$$

and equations (7) - (8).

The multi-scalar variables are assumed like in [Krzeminski Z., 1987]:

$$
\begin{gathered}
x_{11}=\omega_{r}, \\
x_{12}=\psi_{r \alpha} i_{s \beta}-\psi_{r \beta} i_{s \alpha}, \\
x_{21}=\psi_{r \alpha}^{2}+\psi_{r \beta}^{2}, \\
x_{22}=\psi_{r \alpha} i_{s \alpha}+\psi_{r \beta} i_{s \beta} .
\end{gathered}
$$

Introducing the multi-scalar variables (114) - (117), the multi-scalar model of an IM fed by the CSI is obtained: 


$$
\begin{gathered}
\frac{d x_{12}}{d \tau}=-\frac{1}{2 T_{i}} x_{12}-x_{11} x_{22}-x_{11} x_{22} \frac{L_{m}}{2 w_{\sigma}}+\frac{L_{r}}{2 w_{\sigma}}\left(u_{s \beta} \psi_{r \alpha}-u_{s \alpha} \psi_{r \beta}\right)+v_{1}, \\
\frac{d x_{22}}{d \tau}=-\frac{1}{2 T_{i}} x_{22}+x_{11} x_{12}+\frac{R_{r} L_{m}}{2 L_{r} w_{\sigma}} x_{21}+\frac{R_{r} L_{m}}{2 L_{r}} i_{s \alpha}^{2}+\frac{L_{r}}{2 w_{\sigma}}\left(\psi_{r \alpha} u_{s \alpha}+\psi_{r \beta} u_{s \beta}\right)+v_{2},
\end{gathered}
$$

where

$$
\begin{aligned}
& v_{1}=\frac{1}{2 T} \psi_{r \alpha} i_{f \beta}-\frac{1}{2 T} \psi_{r \beta} i_{f \alpha}, \\
& v_{2}=\frac{1}{2 T} \psi_{r \alpha} i_{f \alpha}+\frac{1}{2 T} \psi_{r \beta} i_{f \beta} .
\end{aligned}
$$

Applying the linearization method to (118) - (119), the following expressions are obtained:

$$
\begin{gathered}
v_{1}=\frac{1}{2 T_{i}} m_{1}+x_{11} x_{22}+\frac{L_{m}}{2 w_{\sigma}} x_{11} x_{21}+\frac{L_{r}}{2 w_{\sigma}}\left[u_{s \beta}(k-1) \psi_{r \alpha}-u_{s \alpha}(k-1) \psi_{r \beta}\right]-a_{1} x_{12}, \\
v_{2}=\frac{1}{2 T_{i}} m_{2}-x_{11} x_{21}-\frac{R_{r} L_{m}}{2 w_{\sigma} L_{r}} x_{21}-\frac{R_{r} L_{m}}{2 L_{r}} i_{s \alpha}^{2}-\frac{L_{r}}{2 w_{\sigma}}\left[u_{s \alpha}(k-1) \psi_{r \alpha}+u_{s \beta}(k-1) \psi_{r \beta}\right]+a_{1} x_{22},
\end{gathered}
$$

where

$$
\begin{gathered}
v_{1}=a_{1}\left[i_{f \beta} \psi_{r \alpha}-i_{f \alpha} \psi_{r \beta}\right], \\
v_{2}=-a_{1}\left[i_{f \alpha} \psi_{r \alpha}+i_{f \beta} \psi_{r \beta}\right] .
\end{gathered}
$$

The control variables take the form

$$
\begin{aligned}
& i_{f \alpha}=a_{2} \frac{\psi_{r \alpha} v_{2}-\psi_{r \beta} v_{1}}{x_{21}}, \\
& i_{f \beta}=a_{2} \frac{\psi_{r \alpha} v_{1}+\psi_{r \beta} v_{2}}{x_{21}},
\end{aligned}
$$

where

$$
\begin{aligned}
& a_{1}=\frac{L_{r} T_{i m p}}{2 w_{\sigma} C_{M}}, \\
& a_{2}=a_{1}+\frac{1}{2 T} .
\end{aligned}
$$


The time constant $\mathrm{T}_{\mathrm{i}}$ for simplified for both control method is given

$$
T_{i}=\frac{w_{\sigma} L_{r} T}{R_{s} L_{r}^{2} T+R_{r} L_{m}^{2} T+L_{r} w_{\sigma}},
$$

\subsection{Generalized multi-scalar control of induction machine supplied by CSI or VSI}

A cage induction machine fed by the CSI may be controlled in the same way as with the voltage source inverter (VSI). The generalized control is provided by an IM multi-scalar model formulated for the VSI machine control [Krzeminski Z., 1987]. The (114) - (117) multiscalar variables and additional $\mathrm{u}_{1}$ and $\mathrm{u}_{2}$ variables are used

$$
\begin{aligned}
& u_{1}=\psi_{r \alpha} u_{s \beta}-\psi_{r \beta} u_{s \alpha}, \\
& u_{2}=\psi_{r \alpha} u_{s \alpha}+\psi_{r \beta} u_{s \beta},
\end{aligned}
$$

which are a scalar and vector product of the stator voltage and rotor flux vectors.

The multi-scalar model feedback linearization leads to defining the nonlinear decouplings [Krzeminski Z., 1987]:

$$
\begin{gathered}
U_{1}^{*}=\frac{w_{\sigma}}{L_{r}}\left[x_{11}\left(x_{22}+\frac{L_{m}}{w_{\sigma}} x_{21}\right)+\frac{1}{T_{v}} m_{1}\right], \\
U_{2}^{*}=\frac{w_{\sigma}}{L_{r}}\left[-x_{11} x_{12}-\frac{R_{r} L_{m}}{L_{r}} i_{s}^{2}-\frac{R_{r} L_{m}}{L_{r} w_{\sigma}} x_{21}+\frac{1}{T_{v}} m_{2}\right] .
\end{gathered}
$$

The control variables for an IM supplied by the VSI have the form [Krzeminski Z., 1987]:

$$
\begin{aligned}
& u_{s \alpha}^{*}=\frac{\psi_{r \alpha} U_{2}^{*}-\psi_{r \beta} U_{1}^{*}}{x_{21}}, \\
& u_{s \beta}^{*}=\frac{\psi_{r \alpha} U_{1}^{*}+\psi_{r \beta} U_{2}^{*}}{x_{21}} .
\end{aligned}
$$

The controls (135) - (136) are reference variables treated as input to space vector modulator when the IM is supplied by the VSI.

On the other side, when the IM is fed by the CSI, calculation of the derivatives of (131) (132) multi-scalar variables yields the following relations:

$$
\frac{d u_{1}}{d \tau}=-\frac{R_{r}}{L_{r}} u_{1}-x_{11} u_{2}+\frac{R_{r} L_{m}}{L_{r}} q_{s}-\frac{1}{C_{M}} x_{12}+v_{11},
$$




$$
\frac{d u_{2}}{d \tau}=-\frac{R_{r}}{L_{r}} u_{2}+x_{11} u_{1}+\frac{R_{r} L_{m}}{L_{r}} p_{s}+\frac{1}{C_{M}} x_{22}+v_{22}
$$

where $p_{s}$ and $q_{s}$ are defined in (59) - (60).

By feedback linearization of the system of equations, one obtains

$$
\begin{aligned}
& v_{11}=-\frac{R_{r}}{L_{r}} v_{p 1}-\frac{R_{r} L_{m}}{L_{r}} q_{s}+\frac{1}{C_{M}} x_{12}+x_{11} u_{2}, \\
& v_{22}=-\frac{R_{r}}{L_{r}} v_{p 2}-\frac{R_{r} L_{m}}{L_{r}} p_{s}+\frac{1}{C_{M}} x_{22}-x_{11} u_{1},
\end{aligned}
$$

where

$\mathrm{V}_{\mathrm{p} 1}$ and $\mathrm{v}_{\mathrm{p} 2}$ are the output of subordinated PI controllers.

The control variables of the IM fed by the CSI have the form:

$$
\begin{aligned}
& i_{f \alpha}=-C_{M} \frac{v_{11} \psi_{r \beta}-v_{22} \psi_{r \alpha}}{x_{21}}, \\
& i_{f \beta}=C_{M} \frac{v_{11} \psi_{r \alpha}+v_{22} \psi_{r \beta}}{x_{21}} .
\end{aligned}
$$

As a result, two feedback loops and linear subsystems are obtained (Fig. 15).

\section{The speed observer backstepping}

General conception of the adaptive control with backstepping is presented in references [Payam A. F. \& Dehkordi B. M. 2006, Krstic M.; Kanellakopoulos I.; \& Kokotovic P. 1995]. In [Krstic M.; Kanellakopoulos I.; \& Kokotovic P. 1995] the adaptive back integration observer stability is proved and the stability range is given.

Proceeding in accordance with the adaptive estimator with backstepping conception, one can derive formulae for the observer, where only the state variables will be estimated as well as the rotor angular speed as an additional estimation parameter.

Treating the stator current vector components $\hat{i}_{s \alpha, \beta}$ as the observer output variables (as in [Payam A. F. \& Dehkordi B. M. 2006, Krstic M.; Kanellakopoulos I.; \& Kokotovic P. 1995]) and $v \alpha, \beta$ as the new input variables, which will be determined by the backstepping method, one obtains:

$$
\frac{d \hat{i}_{s \alpha}}{d \tau}=-a_{1} \hat{i}_{s \alpha}+a_{5} \hat{\psi}_{r \alpha}+\hat{\omega}_{r} a_{4} \hat{\psi}_{r \beta}+a_{6} u_{s \alpha}+v_{\alpha},
$$




$$
\begin{gathered}
\frac{d \hat{i}_{s \beta}}{d \tau}=-a_{1} \hat{i}_{s \beta}+a_{5} \hat{\psi}_{r \beta}-\hat{\omega}_{r} a_{4} \hat{\psi}_{r \alpha}+a_{6} u_{s \beta}+v_{\beta}, \\
\frac{d \hat{\psi}_{r \alpha}}{d \tau}=-\frac{R_{r}}{L_{r}} \hat{\psi}_{r \alpha}-\hat{\omega}_{r} \hat{\psi}_{r \beta}+\frac{R_{r} L_{m}}{L_{r}} \hat{i}_{s \alpha}, \\
\frac{d \hat{\psi}_{r \beta}}{d \tau}=-\frac{R_{r}}{L_{r}} \hat{\psi}_{r \beta}+\hat{\omega}_{r} \hat{\psi}_{r \alpha}+\frac{R_{r} L_{m}}{L_{r}} \hat{i}_{s \beta} .
\end{gathered}
$$

In accordance to the backstepping method, the virtual control must be determined together with the observer stabilizing variables. In that purpose, the new $\varsigma_{\alpha}$ and $\varsigma_{\beta}$ variables have been introduced and linked with the stator current estimation deviations (the integral backstepping structure [Krstic M.; Kanellakopoulos I.; \& Kokotovic P. 1995]):

$$
\begin{aligned}
& \frac{d \tilde{\zeta}_{a}}{d \tau}=\tilde{i}_{s \alpha}, \\
& \frac{d \tilde{\zeta}_{b}}{d \tau}=\tilde{i}_{s \beta} .
\end{aligned}
$$

The stator current vector component deviations are treated as the subsystem control variables [Payam A. F. \& Dehkordi B. M. 2006, Krstic M.; Kanellakopoulos I.; \& Kokotovic P. 1995]. Adding and deducting the stabilizing functions, one obtains:

$$
\begin{aligned}
& \frac{d \tilde{\zeta}_{\alpha}}{d \tau}=\tilde{i}_{s \alpha}-\sigma_{\alpha}+\sigma_{\beta}, \\
& \frac{d \tilde{\zeta}_{\beta}}{d \tau}=\tilde{i}_{s \beta}-\sigma_{\alpha}+\sigma_{\beta},
\end{aligned}
$$

where

$$
\sigma_{\alpha}=-c_{1} \tilde{\varsigma}_{\alpha}, \sigma_{\beta}=-c_{1} \tilde{\varsigma}_{\beta}
$$

by introducing the deviation defining variable, one obtains:

$$
\begin{aligned}
& z_{\alpha}=\tilde{i}_{s \alpha}+c_{1} \tilde{\varsigma}_{\alpha}, \\
& z_{\beta}=\tilde{i}_{s \beta}+c_{1} \tilde{\varsigma}_{\beta} .
\end{aligned}
$$

Transformation of (152) - (153) leads to:

$$
\frac{d \tilde{\varsigma}_{\alpha}}{d \tau}=z_{\alpha}-c_{1} \tilde{\varsigma}_{\alpha}
$$




$$
\frac{d \tilde{\varsigma}_{\beta}}{d \tau}=z_{\beta}-c_{1} \tilde{\varsigma}_{\beta}
$$

Calculation of the (152) - (153) deviation derivatives gives:

$$
\begin{aligned}
& \dot{z}_{\alpha}=a_{5} \tilde{\psi}_{r \alpha}+a_{4}\left[\hat{\omega}_{r} \tilde{\psi}_{r \beta}+\tilde{\omega}_{r}\left(\hat{\psi}_{r \beta}-\tilde{\psi}_{r \beta}\right)\right]+v_{\alpha}+c_{1} \tilde{i}_{s \alpha}, \\
& \dot{z}_{\beta}=a_{5} \tilde{\psi}_{r \beta}-a_{4}\left[\hat{\omega}_{r} \tilde{\psi}_{r \alpha}+\tilde{\omega}_{r}\left(\hat{\psi}_{r \alpha}-\tilde{\psi}_{r \alpha}\right)\right]+v_{\beta}+c_{1} \tilde{i}_{s \beta} .
\end{aligned}
$$

By selecting the following Lyapunov function

$$
V=\tilde{\varsigma}_{\alpha}^{2}+\tilde{\varsigma}_{\beta}^{2}+z_{\alpha}^{2}+z_{\beta}^{2}+\tilde{\psi}_{r \alpha}^{2}+\tilde{\psi}_{r \beta}^{2}+\frac{1}{\gamma} \tilde{\omega}_{r}^{2}
$$

calculating the derivative and substituting the respective expressions, new correction elements can be determined, treated in the speed observer backstepping as the input variables. The Lyapunov function is determined for the dynamics of the $\varsigma_{\alpha, \beta}, z_{\alpha, \beta}$ variables and for the rotor flux components. Calculating the (158) derivative, one obtains:

$$
\begin{aligned}
& \dot{V}=-c_{1} \tilde{\varsigma}_{\alpha}^{2}-c_{1} \tilde{\varsigma}_{\beta}^{2}-c_{2} z_{\alpha}^{2}-c_{2} z_{\beta}^{2}-\frac{R_{r}}{L_{r}} \tilde{\psi}_{r \alpha}^{2}-\frac{R_{r}}{L_{r}} \tilde{\psi}_{r \beta}^{2}+z_{\alpha}\left(a_{5} \tilde{\psi}_{r \alpha}+\hat{\omega}_{r} a_{4} \tilde{\psi}_{r \beta}+\tilde{\omega}_{r} a_{4}\left(\hat{\psi}_{r \beta}-\tilde{\psi}_{r \beta}\right)+\right. \\
& \left.+v_{\alpha}+c_{1} \tilde{i}_{s \alpha}+c_{2} z_{\alpha}+\tilde{\zeta}_{\alpha}\right)+z_{\beta}\left(a_{5} \tilde{\psi}_{r \beta}-\hat{\omega}_{r} a_{4} \tilde{\psi}_{r \alpha}-\tilde{\omega}_{r} a_{4}\left(\hat{\psi}_{r \alpha}-\tilde{\psi}_{r \alpha}\right)+v_{\beta}+c_{1} \tilde{i}_{s \beta}+c_{2} z_{\beta}+\tilde{\zeta}_{\beta}\right)+ \\
& \tilde{\psi}_{r \alpha}\left(-\frac{R_{r}}{L_{r}} \tilde{\psi}_{r \alpha}-\hat{\omega}_{r} \tilde{\psi}_{r \beta}-\tilde{\omega}_{r}\left(\hat{\psi}_{r \beta}-\tilde{\psi}_{r \beta}\right)\right)+\tilde{\psi}_{r \beta}\left(-\frac{R_{r}}{L_{r}} \tilde{\psi}_{r \beta}+\hat{\omega}_{r} \tilde{\psi}_{r \alpha}+\tilde{\omega}_{r}\left(\hat{\psi}_{r \alpha}-\tilde{\psi}_{r \alpha}\right)\right) .
\end{aligned}
$$

The input variables $\mathrm{v} \alpha, \beta$, resulting directly from (159), should include the estimated variables and the estimation deviations:

$$
\begin{aligned}
& v_{\alpha}=-a_{5} \tilde{\psi}_{r \alpha}-\hat{\omega}_{r} a_{4} \tilde{\psi}_{r \beta}-c_{1} \tilde{i}_{s \alpha}-c_{2} z_{\alpha}-\tilde{\varsigma}_{\alpha}, \\
& v_{\beta}=-a_{5} \tilde{\psi}_{r \beta}+\hat{\omega}_{r} a_{4} \tilde{\psi}_{r \alpha}-c_{1} \tilde{i}_{s \beta}-c_{2} z_{\beta}-\tilde{\varsigma}_{\beta} .
\end{aligned}
$$

Taking (160) - (161) into account, the deviation derivatives may be written in the form:

$$
\begin{gathered}
\dot{z}_{\alpha}=\tilde{\omega}_{r} a_{4}\left(\hat{\psi}_{r \beta}-\tilde{\psi}_{r \beta}\right)-c_{2} z_{\alpha}-\tilde{\varsigma}_{\alpha}, \\
\dot{z}_{\beta}=-\tilde{\omega}_{r} a_{4}\left(\hat{\psi}_{r \alpha}-\tilde{\psi}_{r \alpha}\right)-c_{2} z_{\beta}-\tilde{\varsigma}_{\beta} .
\end{gathered}
$$

Using (162) - (163), the Lyapunov function may be written as follows:

$$
\dot{V}=-c_{1} \tilde{\varsigma}_{\alpha}^{2}-c_{1} \tilde{s}_{\beta}^{2}-c_{2} z_{\alpha}^{2}-c_{2} z_{\beta}^{2}+\tilde{\omega}_{r} a_{4}\left[z_{\alpha}\left(\hat{\psi}_{r \beta}-\tilde{\psi}_{r \beta}\right)-z_{\beta}\left(\hat{\psi}_{r \alpha}-\tilde{\psi}_{r \alpha}\right)+\frac{1}{\gamma} \dot{\hat{\omega}}_{r}\right] .
$$

The observer, defined by the (143) - (146) and (154) - (155) equations, is a backstepping type estimator. 
In the (160) - (163) expressions the rotor flux deviations appear, which may be neglected without any change to the observer properties (143) - (146). Besides, the $\tilde{\varsigma}_{\alpha^{\prime} \beta}$ deviations in (160) - (161) may be zero, thus lowering the observer order. Assuming the simplifications, one obtains

$$
\begin{aligned}
& v_{\alpha}=-c_{1} \tilde{i}_{s \alpha}-c_{2} z_{\alpha}, \\
& v_{\beta}=-c_{1} \tilde{i}_{s \beta}-c_{2} z_{\beta},
\end{aligned}
$$

and

$$
\dot{\hat{\omega}}_{r}=\gamma a_{4}\left(z_{\beta} \hat{\psi}_{r \alpha}-z_{\alpha} \hat{\psi}_{r \beta}\right) .
$$

where

$\mathrm{C} 1, \mathrm{C} 2, \gamma$ are constant gains,

$$
a_{4}=\frac{L_{m}}{w_{\sigma}}, a_{5}=\frac{R_{r} L_{m}}{L_{r} w_{\sigma}}, a_{6}=\frac{L_{r}}{w_{\sigma}} .
$$

In Fig. 10, 11 the backstepping speed observer test is shown. When the load torque is set to $\sim-0.1$ p.u. the rotor speed in backstepping observer is more precisely estimated than e.g. Krzeminski's speed observer.

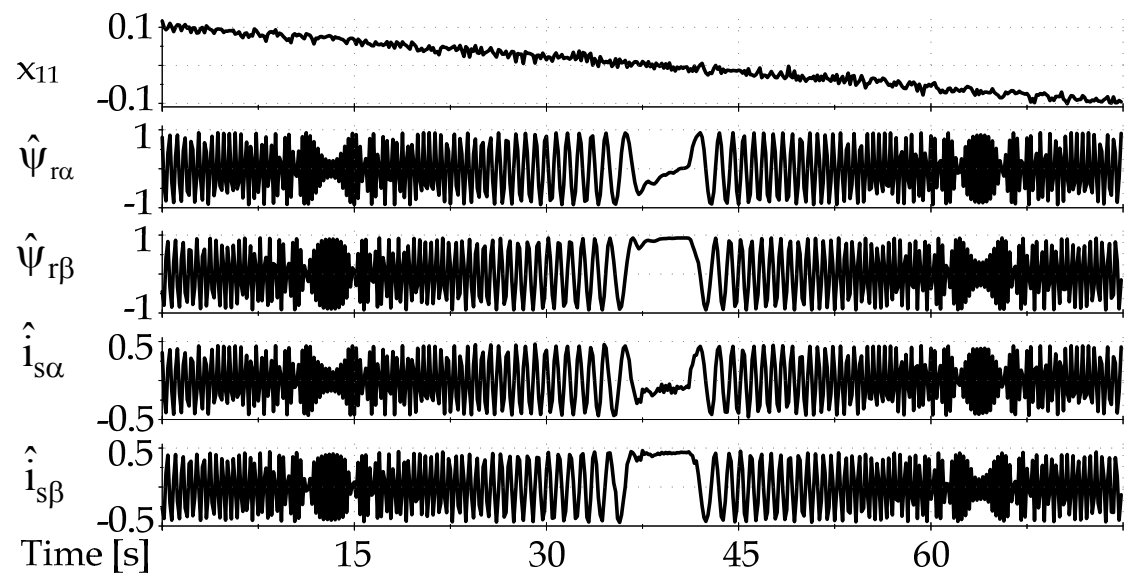

Figure 10. The Speed observer test: the estimated rotor speed $\mathrm{x}_{11}$ is changed from 0.1 to -0.1 p.u., the rotor flux and stator current coefficients are shown 


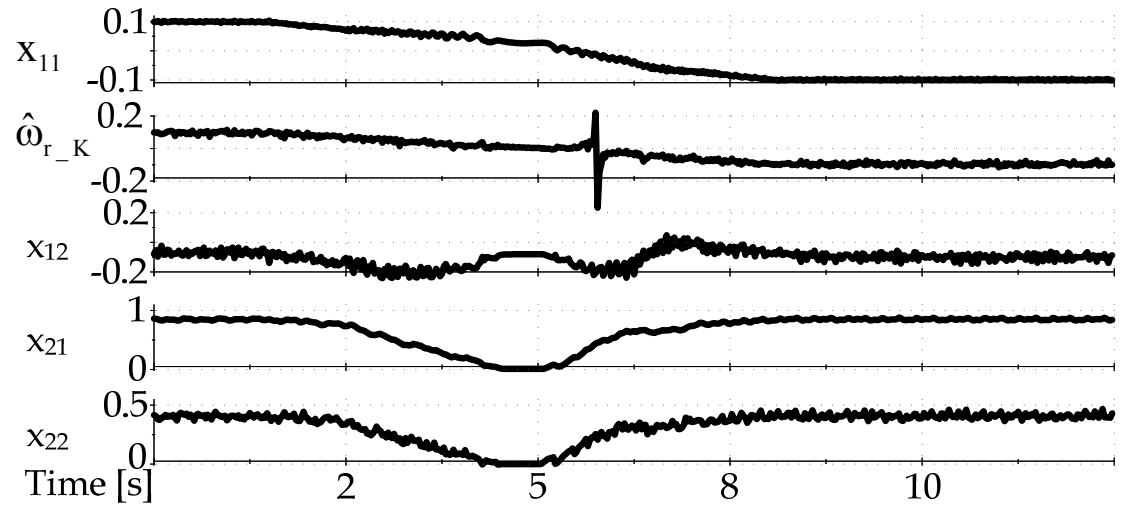

Figure 11. The Speed observer test: the estimated rotor speed $\mathrm{x}_{11}$ in backstepping observer is changed from 0.1 to -0.1 p.u., the estimated rotor speed $\hat{\omega}_{r_{-} K}$ by Krzeminski's speed observer [Krzeminski Z., 1999] and the multi-scalar variable: $\mathrm{x}_{12}, \mathrm{x}_{21}, \mathrm{x}_{22}$ are shown . The load torque $\mathrm{m}_{0}$ is set to -0.1 p.u.

\section{The control system structures}

In Fig. 12 and Fig. 14 the voltage and current multi-scalar control system structure is shown. These structures are based on four PI controllers and contain: the modulator, the speed observer and decouplings blocks .

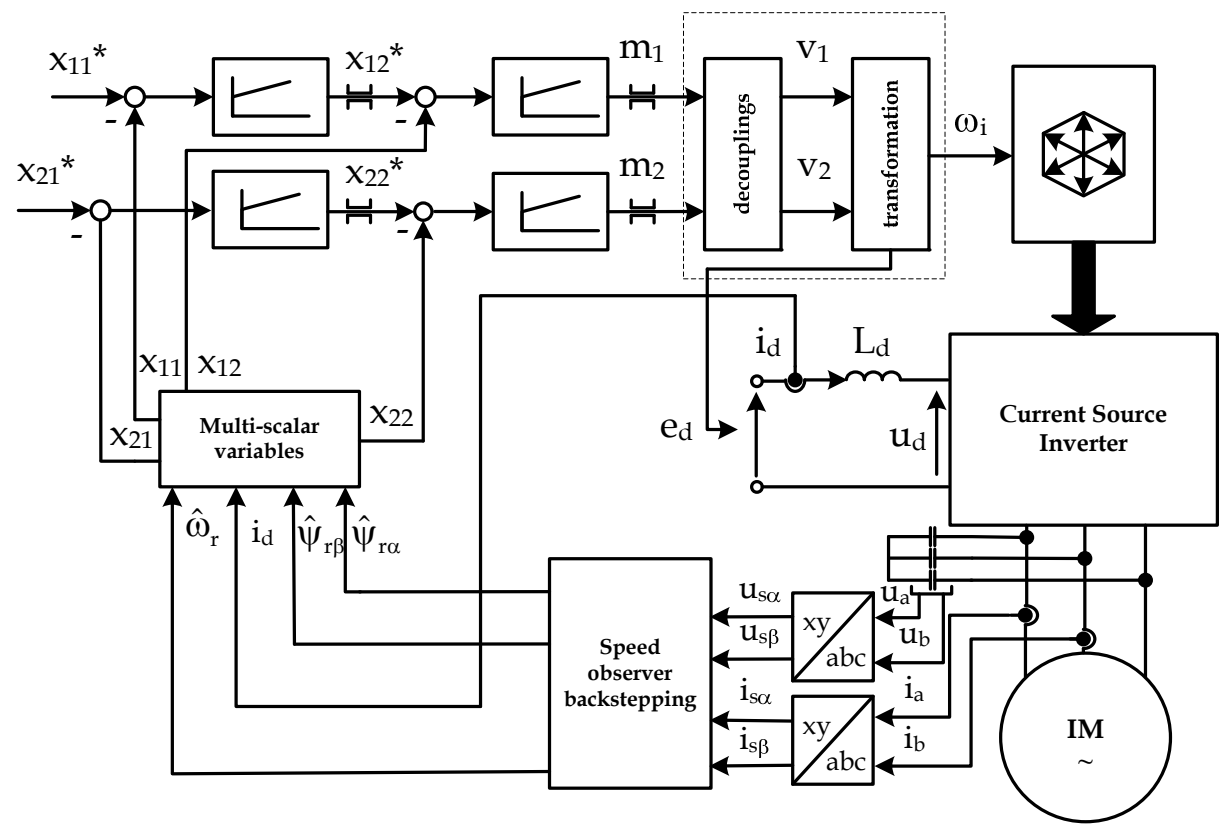

Figure 12. The voltage multi-scalar control system structure 


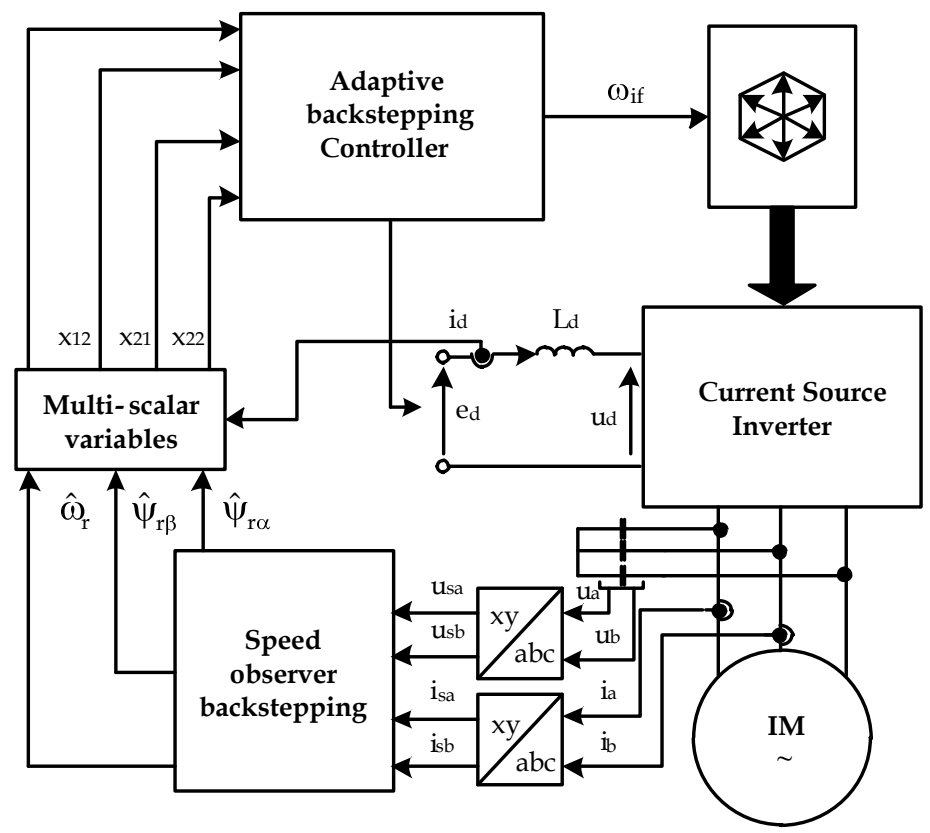

Figure 13. The voltage multi-scalar adaptive backstepping control system structure

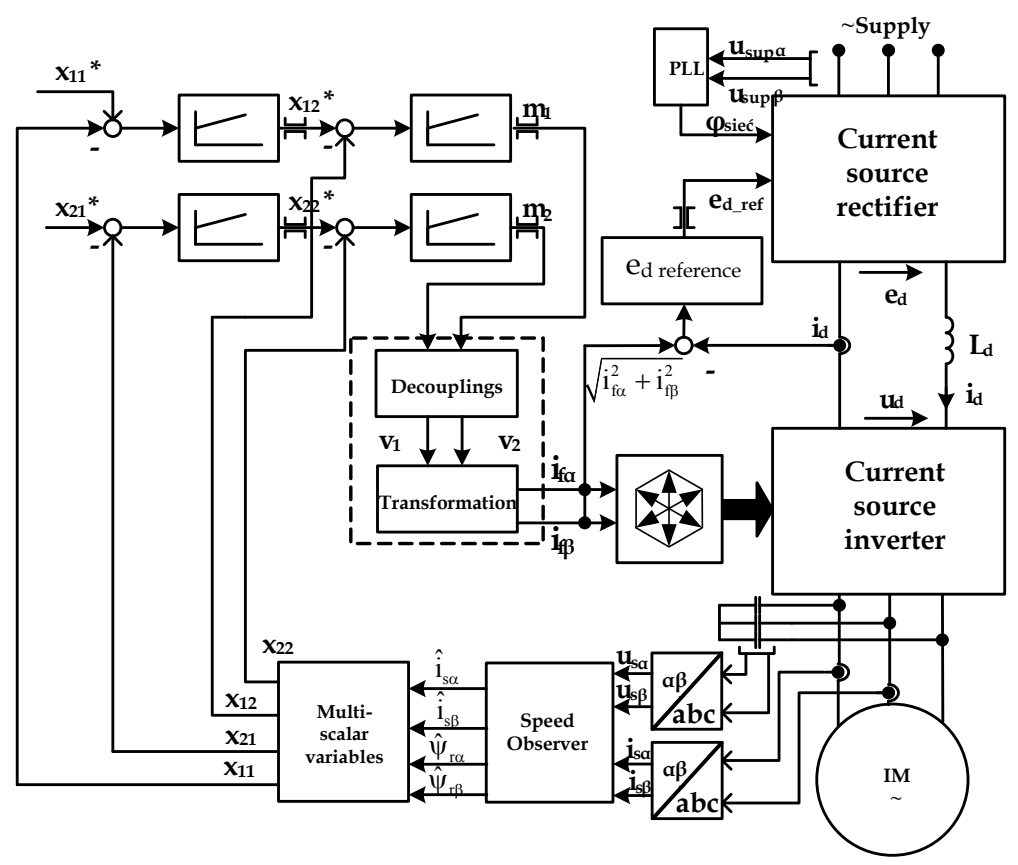

Figure 14. The current multi-scalar control system structure. 


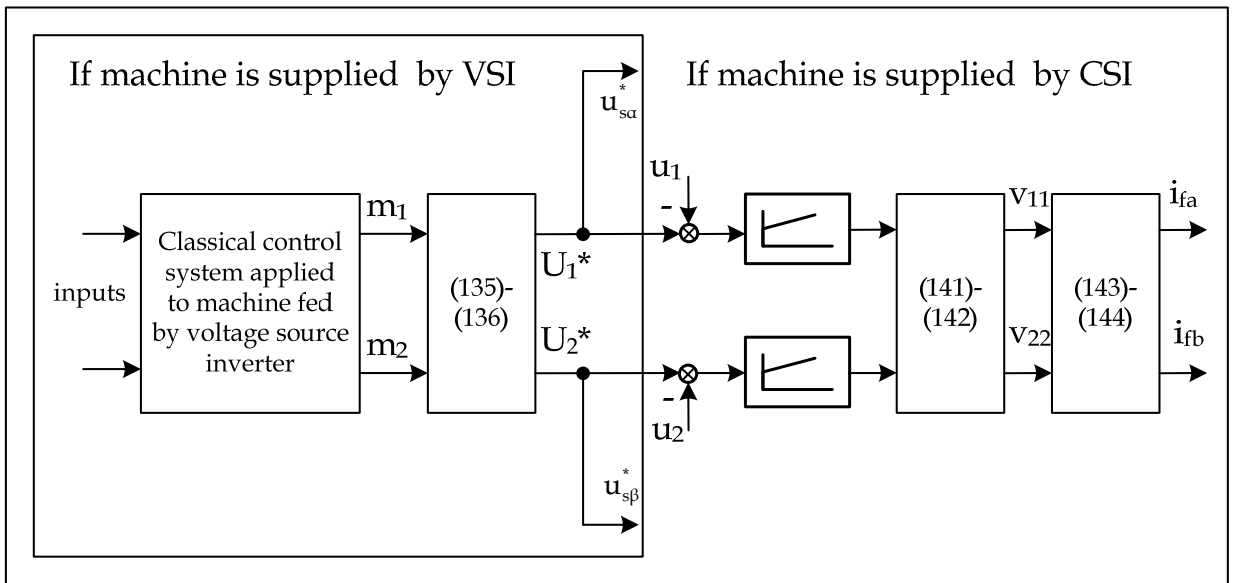

Figure 15. Generalized Multi-scalar Control System of Induction Machine supplied by CSI or VSI.

In Fig. 14 the ed_ref value is determined in ed reference block. The ed reference block can be PI current controller or other controller.

In Fig. 13 the voltage multi-scalar adaptive backstepping control system structure is shown.

In Fig. 15 generalized multi-scalar control system structure is presented. This control structure is divided into two parts: the control system of IM fed by VSI and the control system of IM fed by CSI.

\section{Experimental verification of the control systems}

The tests were carried out in a $5.5 \mathrm{~kW}$ drive system. The motor parameters are given in Table 2 and the main per unit values in Table 3. In Fig. 16, 17 motor start-up and reverse for control system presented in chapter 4.1-4.2 are shown. In Fig. 18, 19 motor start-up and reverse for control system presented in chapter 5 are shown. Fig. 20,21 presents the same steady state like previous but for adaptive backstepping control system (chapter 4.3). Fig. 22 presents diagram of stator currents and voltages when motor is starting up for voltage control system (chapter 4.3). In Fig. 23 load torque setting to 0.7 p.u. for current control is presented. In Fig. 24, 25 the id current and the sinusoidal stator voltage and stator current are presented. 


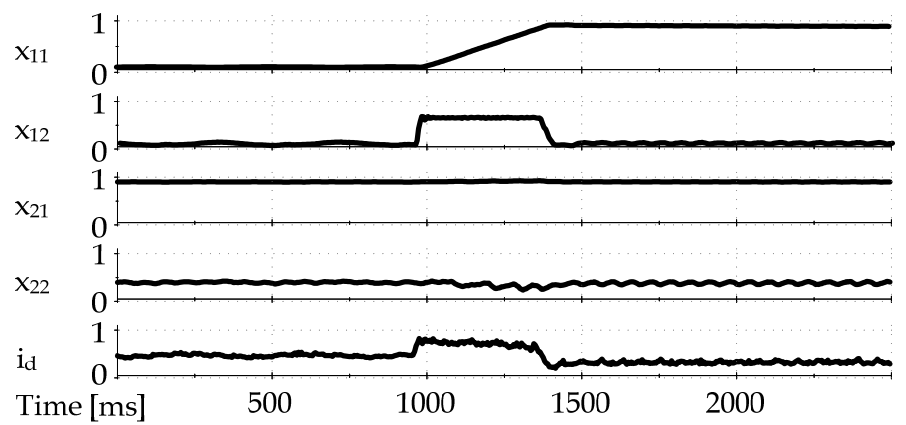

Figure 16. Motor start-up (chapter 4.1- 4.2)

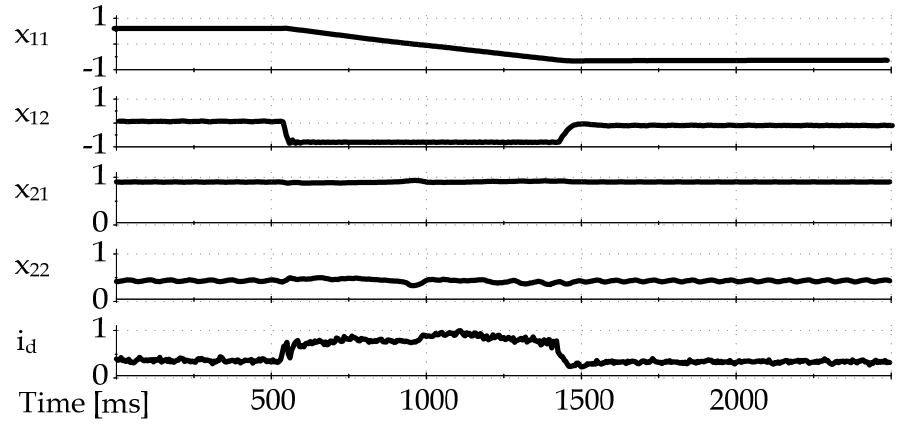

Figure 17. Motor reverse (chapter 4.1- 4.2)

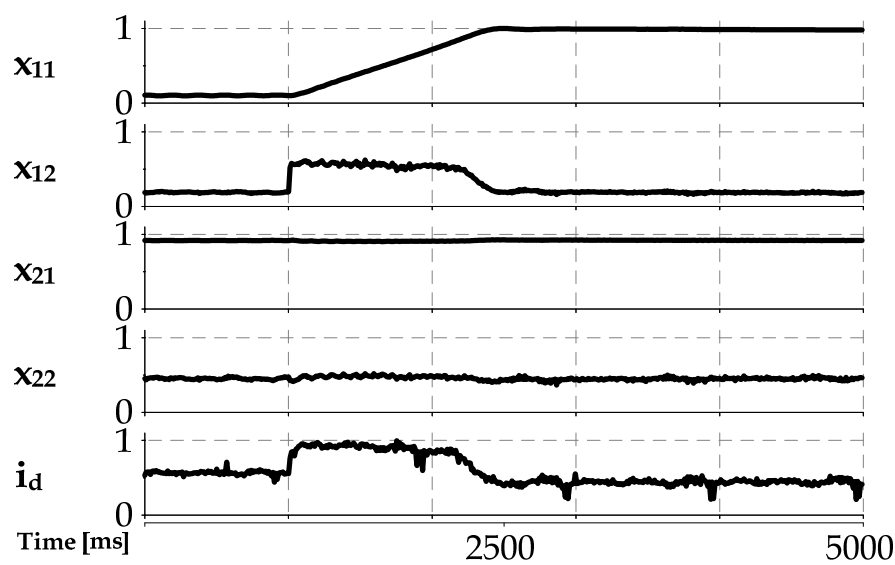

Figure 18. Motor start-up (chapter 5) 


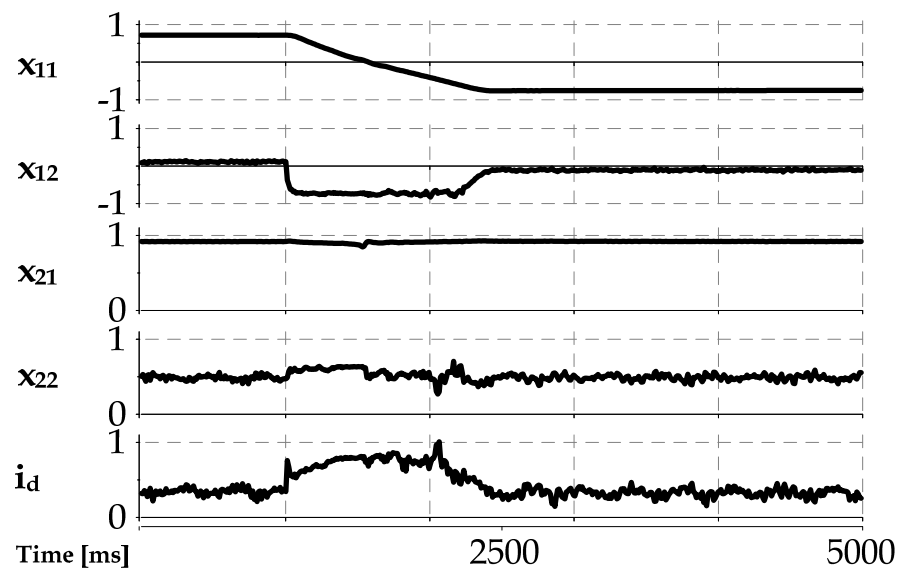

Figure 19. Motor reverse (chapter 5)
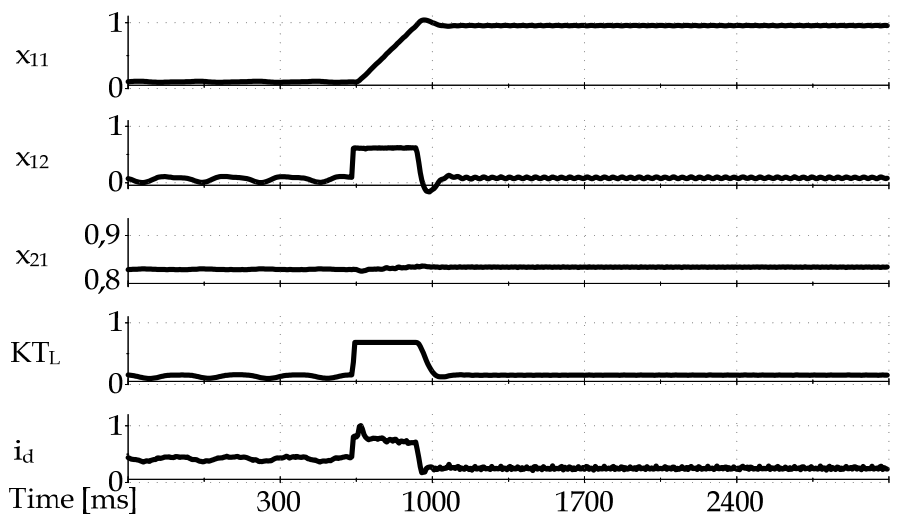

Figure 20. Motor start-up (chapter 4.3)

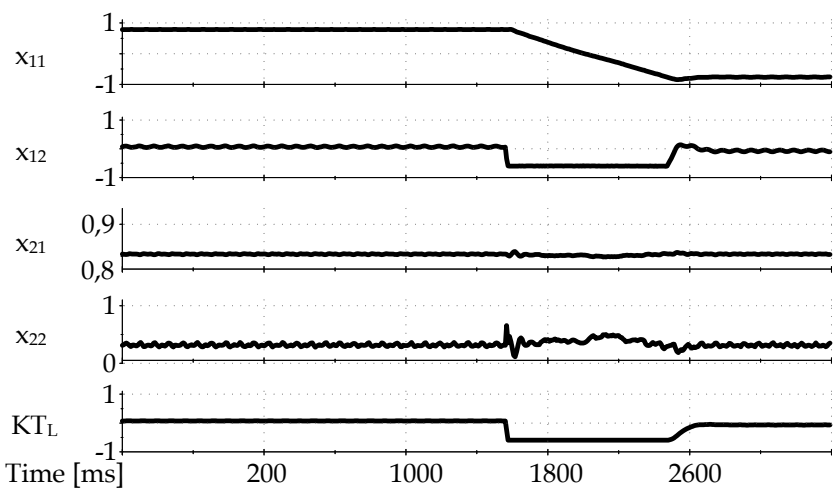

Figure 21. Motor reverse (chapter 4.3) 


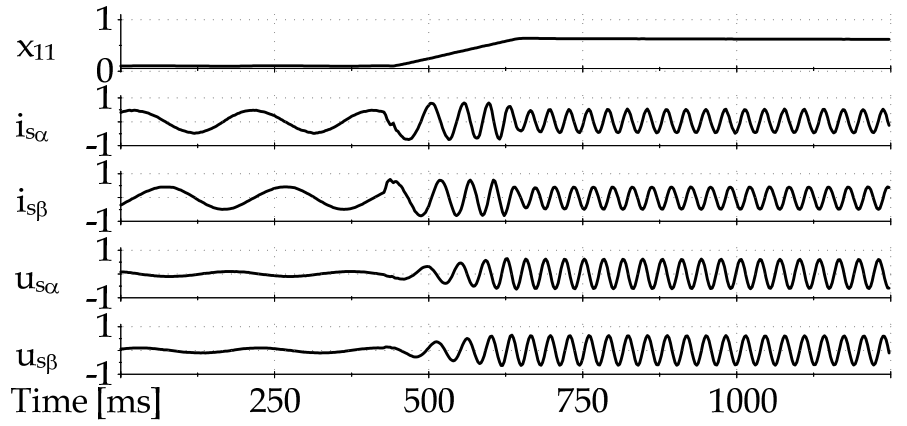

Figure 22. The currents and voltages

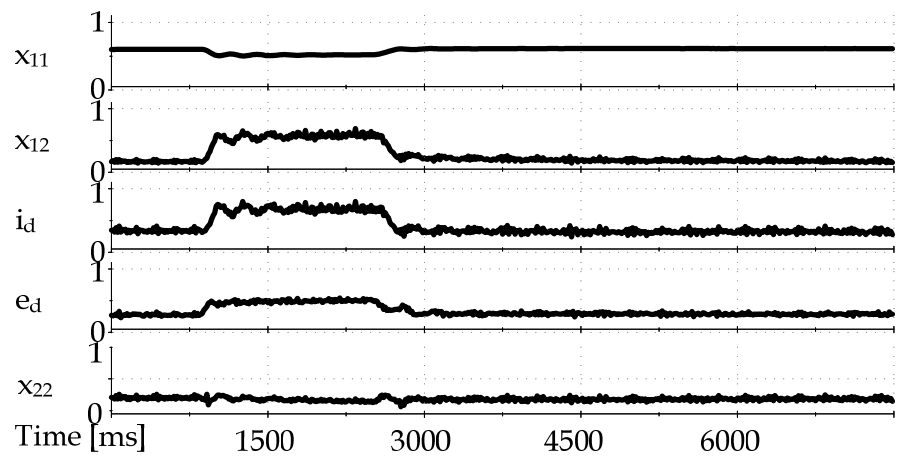

Figure 23. Load torque is set to 0.7 p.u. (chapter 5)

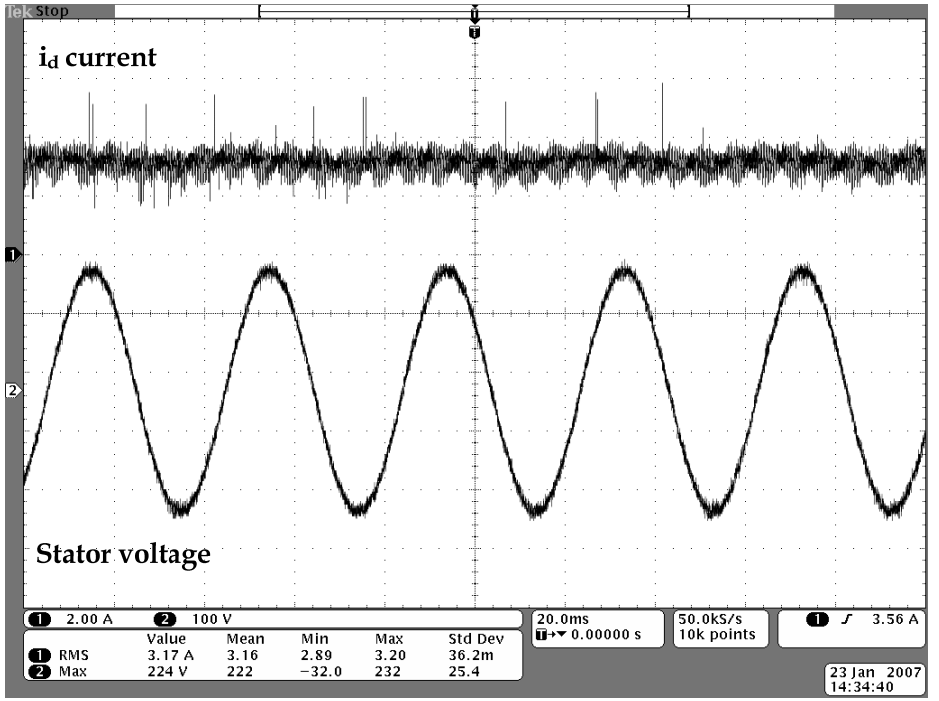

Figure 24. id current and the stator voltage 


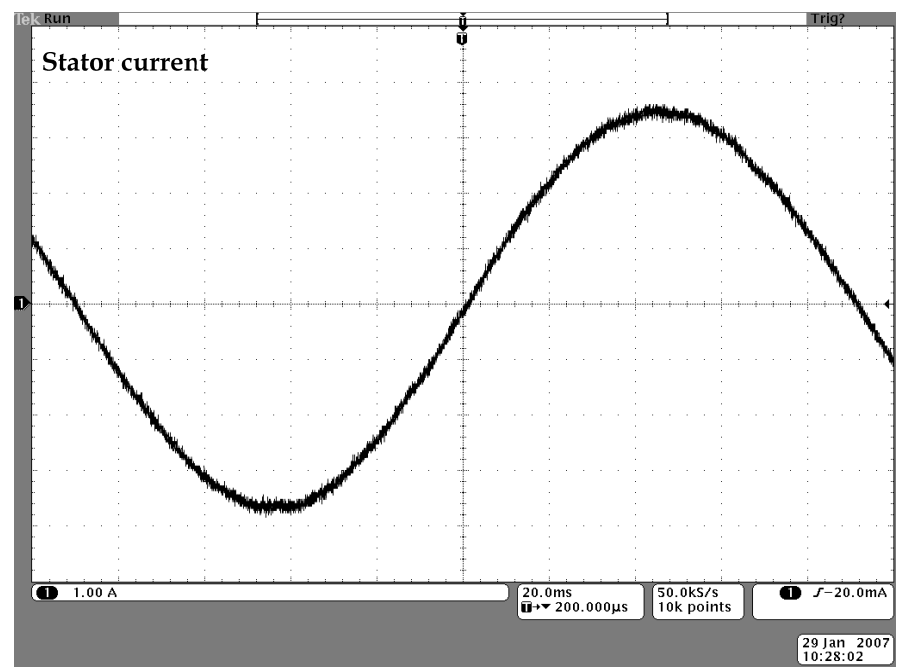

Figure 25. The stator current in stationary state.

where:

$\mathrm{x}_{11}$ is the rotor speed, $\mathrm{x}_{12}$ is the variable proportional to electromagnetic torque, $\mathrm{x}_{21}$ is the square of rotor flux and $\mathrm{x}_{22}$ is the additional variables, $\mathrm{i}_{\mathrm{d}}$ is the dc-link current, $\mathrm{u}_{\mathrm{s} \alpha, \beta}$ are the capacitor voltage components, KTL is correction element (load torque), is $\alpha, \beta$ are the stator current components.

\section{Conclusion}

In this chapter two approaches to control of induction machine supplied by current source converter are presented. The first of them is voltage multi-scalar control based on PI controllers or backstepping controller. The voltage approach seems to be a better solution than the second one: current control, because the control system structure is more simple than the current control structure. The voltage in dc-link is the control variables obtained directly from decouplings. The current in dc-link is not kept at constant value but its value depend on induction machine working point. The current control gives higher losses in dc-link and higher transistor power losses than the voltage control. The power losses can be minimized by modulation index control method but the control system is more complicated. Both control systems lead to decoupling control path and sinusoidal stator current and voltage when space vector modulation of transistors is applied. 


\begin{tabular}{|l|l|}
\hline PARAMETER & VALUE \\
\hline$P_{n}$ (motor power) & $5.5 \mathrm{~kW}$ \\
\hline$U_{n}$ (phase to phase voltage) & $400 \mathrm{~V}$ \\
\hline In (current) & $10.9 \mathrm{~A}$ \\
\hline J (interia) & $0.0045 \mathrm{kgm}^{2}$ \\
\hline $\mathrm{n}_{\mathrm{n}}$ (rotor speed) & $1500 \mathrm{rpm}$ \\
\hline \hline PARAMETER & PER UNIT VALUES \\
\hline \hline $\mathrm{R}_{\mathrm{s}}$ (stator resist.) & 0.045 \\
$\mathrm{R}_{\mathrm{r}}$ (rotor resist.) & 0.055 \\
Lm (mutual-flux induct.) & 1.95 \\
Ls (stator induct.) & 2.05 \\
Lr (rotor induct.) & 2.05 \\
\hline \hline Current Source Converter & 0.1 \\
\hline \hline C (capacitor in dc-link) & 0.002 \\
$R_{d}$ (inductor resist.) & 0.2 \\
C $\mathrm{M}, \mathrm{L}$ (input-output caps) &
\end{tabular}

Table 2. The motor drive system parameters

\begin{tabular}{|l|l|}
\hline DEFINITION & DESCRIPTION \\
\hline \hline$U_{b}=\sqrt{3} U_{n}$ & base voltage \\
\hline$I_{b}=I_{n}$ & base current \\
\hline$z_{b}=U_{b} / I_{b}$ & base impedance \\
\hline
\end{tabular}

Table 3. Definition of per unit values

\section{Author details}

Marcin Morawiec

Gdansk University of Technology, Faculty of Electrical and Control Engineering, Poland

\section{References}

Adamowicz M.; Guzinski J.; Minimum-time minimum-loss speed sensorless control of induction motors under nonlinear control, Compatibility in Power Electronics 2005.

Bassi E.; Benzi F.P.; Bolognani S.; Buja G.S., A field orientation scheme for current-fed induction motor drives based on the torque angle closed-loop control, IEEE Transactions on Industry Applications, Volume 28, Issue 5, Sept.-Oct. 1992 Pages: 1038 - 1044.

Glab (Morawiec) M.; Krzeminski Z. \& Włas M., The PWM current source inverter with IGBT transistors and multiscalar model control system, 11th European Conference on Power Electronics and Applications, IEEE 2005. 
Glab (Morawiec) M.; Krzeminski Z.; Lewicki A., Multiscalar control of induction machine supplied by current source inverter, PCIM 2007, Nuremberg 2007.

Fuschs F. \& Kloenne A. dc-link and Dynamic Performance Features of PWM IGBT Current Source Converter Induction Machine Drives with Respect to Industrial Requirements, IPEMC 2004, Vol. 3, 14-16 August 2004.

Kwak S.; Toliyat H.A., A Current Source Inverter With Advanced External Circuit and Control Method, IEEE Transactions on Industry Applications, Volume 42, Issue 6, Nov.-dec. 2006 Pages: 1496 - 1507.

Klonne A. \& Fuchs W.F., High dynamic performance of a PWM current source converter induction machine drive, EPE 2003, Toulouse.

Krstic M.; Kanellakopoulos I.; \& Kokotovic P., Nonlinear and Adaptive Control Design, John Wiley E Sons, 1995.

Krzeminski Z., A new speed observer for control system of induction motor. IEEE Int. Conference on Power Electronics and Drive Systems, PESC'99, Hong Kong, 1999.

Krzeminski Z., Nonlinear control of induction motor, Proceedings of the 10th IFAC World Congress, Munich 1987.

Morawiec M., Sensorless control of induction machine supplied by current source inverter , PhD Thesis, Gdansk University of Technology 2007.

Nikolic Aleksandar B., Jeftenic Borislav I.: Improvements in Direct Torque Control of Induction Motor Supplied by CSI, IEEE Industrial Electronics, IECON 2006 - 32nd Annual Conference on Industrial Electronics.

Payam A. F.; Dehkordi B. M.; Nonlinear sliding-mode controller for sensorless speed control of DC servo motor using adaptive backstepping observer, International Conference on Power Electr., PEDES '06, 2006.

Salo M.; Tuusa H., Vector-controlled PWM current-source-inverter-fed induction motor drive with a new stator current control method, IEEE Transactions on Industrial Electronics, Volume 52, Issue 2, April 2005 Pages: 523 - 531.

Tan H.; \& Chang J.; Adaptive Backstepping control of induction motor with uncertainties, in Proc. the American control conference, California, June 1999, pp. 1-5.

Young Ho Hwang; Ki Kwang Park; Hai Won Yang; Robust adaptive backstepping control for efficiency optimization of induction motors with uncertainties, ISIE 2008. 